\title{
Radicals and Polymers
}

\author{
Peter Nesvadba* \\ KGF-SCS Senior Industrial Investigator Award 2016
}

\begin{abstract}
This article describes some selected results of my 30 years as an industrial researcher. During this time, I had the chance to work on many very different projects. About two thirds of them were dealing with the fascinating interaction of radicals and polymers. Of the more than 350 million tons of industrial polymers produced worldwide every year, about $50 \%$ are made by the radical polymerization of monomers that are often stabilized against undesired premature polymerization by addition of polymerization inhibitors. Stabilizers are necessary to protect the majority of polymeric materials during their service life from radical degradation processes triggered by oxygen, heat or light. Modification of the polymeric architecture can be easily achieved via radical polymer analogous reactions. One of the most important developments in polymer science in the last 25 years is controlled radical polymerization. Recently, radical bearing redox-active polymers emerged as promising in energy storage applications, for example, in organic radical batteries. Our contributions to the fields mentioned above are described with examples of: a) novel benzofuranone stabilizers for polymers; $b$ ) the serendipidous discovery of novel dyestuffs; $c$ ) eco-friendly polymerization inhibitors; $d$ ) novel nitroxides and alkoxyamines for the first industrial realization of controlled radical polymerization; $e$ ) novel and safe radical initiators; $f$ ) nitroxide radicals bearing polymers for electrochemical applications.
\end{abstract}

Keywords: Alkoxyamine · Aminoxyl · Antioxidant - ATRP · ATRA · Autoxidation · Bargellini reaction · Cool black - Controlled polymerization - CRDRP · CR-PP - Dibenzonaphthyron · Group transfer polymerization · HALS

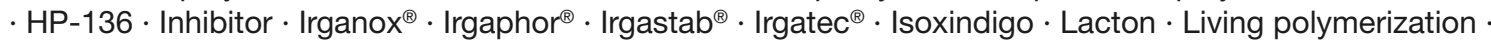
Monomer · Nitroxide · NMP · Oracet ${ }^{\oplus}$ Orange LGP - PTMA · Peroxide · Organic radical battery · Process stabilizer $\cdot$ Radical $\cdot$ Redox-active polymer $\cdot$ Redox shuttle $\cdot$ Stabilization

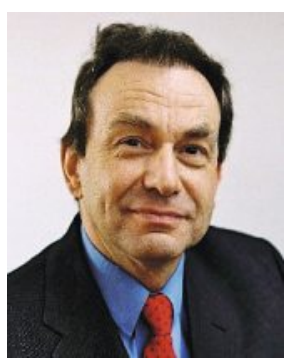

Peter Nesvadba studied at the University of Chemistry and Technology in Prague and got his $\mathrm{PhD}$ in Organic Chemistry from the University of Fribourg in Switzerland (Prof. Dr. A. Gossauer) in 1986. In 1987, he started his industrial career with the additives division of CibaGeigy in Marly, working on lubricant additives, novel antioxidants for polymers and novel dyes. During 1993-1994

${ }^{\star}$ Correspondence: Prof. Dr. P. Nesvadba

BASF Schweiz AG

R-1059.6.05

Mattenstrasse 22

$\mathrm{CH}-4058$ Basel

E-mail: peter.nesvadba@basf.com he performed research on polymerization inhibitors in the Ciba research center in Ardsley, USA. After his return to Switzerland he began working on a variety of projects including nitroxide mediated polymerization, novel radical initiators, use of nitroxides for electrochemical applications, materials for organic electronics, photoinitiators and agrochemicals. He is currently working as a Senior Research Fellow at BASF Schweiz AG in Basel. In 2007 Peter Nesvadba obtained his habilitation in Organic Chemistry at the University of Fribourg and was appointed Titular Professor for Organic Chemistry in 2011. Peter Nesvadba has authored or co-authored 39 journal papers, 3 book chapters and 103 published patent applications. He and his colleagues received 3 Ciba research awards, and notably the Sandmeyer Award of the Swiss Chemical Society (2011).

\section{Radicals in the Degradation of Polymers}

"Life is a constant battle to avoid becoming rancid". This quotation ${ }^{[1]}$ by Garry G. Duthie, a distinguished scientist in the field of oxidative stress and antioxidants, brings succinctly to the point the results of action of reactive radicals (IUPAC discourages $^{[2]}$ the term 'free radical'), not only within living organisms, but also in nonliving organic materials.

The modern world as we know it would not be possible without synthetic polymers of which about 350 million tons are produced $^{[3]}$ worldwide every year. Most polymers, synthetic or biopolymers, undergo photo- and/or thermo-oxidative degradation. This degradation starts already in the early stages of manufacturing of polymers and occurs during their whole service life. The consequence is the loss of useful properties such as flexibility, toughness, strength, or color, and represents significant economic losses. The mechanistic understanding of polymer degradations resulted in the auto-oxidation scheme (AOS) which was established about 70 years ago by Bolland, Gee and co-workers ${ }^{[4]}$ (Scheme 1).

The auto-oxidation of polymers is an autocatalytic chain process consisting of initiation, propagation, chain branching and termination reactions. It begins with the formation of initiating radicals (reaction 1 , Scheme 1) when the polymer is exposed to elevated temperature, light, transition metal impurities (catalyst residues) or to high shear stress occurring during compounding, extrusion and molding of polymeric materials.

The energetic plausibility of elementary steps of AOS was recently revised ${ }^{[5]}$ 


\begin{tabular}{|c|c|c|c|}
\hline \multicolumn{4}{|l|}{ Initiation } \\
\hline R-H (Polymer) & & $\mathrm{R}^{\bullet}$ & (1) \\
\hline \multicolumn{4}{|l|}{ Propagation } \\
\hline $\mathrm{R}^{\bullet}+\mathrm{O}_{2}$ & & $\mathrm{ROO}^{\bullet}$ & (2) \\
\hline $\mathrm{ROO} 0^{\bullet}+\mathrm{R}-\mathrm{H}$ & $\longrightarrow$ & $\mathrm{ROOH}+\mathrm{R}^{\bullet}$ & (3) \\
\hline \multicolumn{4}{|l|}{ Chain branching } \\
\hline $\mathrm{ROOH}$ & $\longrightarrow$ & $\mathrm{RO}^{\bullet}+\bullet \mathrm{OH}^{-}$ & (4) \\
\hline $2 \mathrm{ROOH}$ & & $\mathrm{ROO}^{\bullet}+\mathrm{RO}^{\bullet}+\mathrm{H}_{2} \mathrm{O}$ & $(5)$ \\
\hline $\mathrm{RO}^{\bullet}+\mathrm{R}-\mathrm{H}$ & 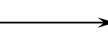 & $\mathrm{ROH}+\mathrm{R}^{\bullet}$ & (6) \\
\hline $\mathrm{HO}^{\bullet}+\mathrm{R}-\mathrm{H}$ & & $\mathrm{H}_{2} \mathrm{O}+\mathrm{R}^{\bullet}$ & (7) \\
\hline $2 \mathrm{ROO}^{\bullet}$ & & $2 \mathrm{RO}^{\bullet}+\mathrm{O}_{2}$ & (8) \\
\hline \multicolumn{4}{|l|}{ Termination } \\
\hline $2 R^{\bullet}$ & fast & & (9) \\
\hline$R O O^{\bullet}+R^{\bullet}$ & fast & non radical & (10) \\
\hline & fast & & (11) \\
\hline
\end{tabular}

Scheme 1. Autooxidation scheme. by Cotee and coworkers. Importantly, their high level quantum chemical calculations have shown that the propagation step (reaction 3), i.e. the hydrogen abstraction from the substrate by the peroxyl radical $(\mathrm{RH}+$ $\left.\mathrm{ROO}^{\bullet} \rightarrow \mathrm{R}^{\bullet}+\mathrm{ROOH}\right)$ is characterized by largely positive Gibbs free energy (10-65 $\mathrm{kJ} \mathrm{mol}^{-1}$ ) for most regular polymers with saturated chains (polypropylene, polyethylene, polyvinyl chloride, polyvinyl acetate, polyurethane, poly(methyl methacrylate), etc. Only when the formed radical center is stabilized by adjacent conjugated double bonds or by two suitable functional groups, is the propagation step exoergic. In real polymers, structural defects are practically always present, such as terminal or internal double bonds, formed either during polymerization or in the degradation process itself, which then allows the autooxidation to proceed. The counter argument would be that pure polymers without any defects should be significantly more resistant towards oxidative degradation!

Accurate quantum chemical calculations were also employed ${ }^{[6]}$ to investigate the mechanism for the ozone-initiated oxidation of $\mathrm{C}-\mathrm{H}$ bonds of saturated hydrocarbons and polymers.

The ubiquitous use of polymers would not be possible without their efficient stabilization against degradation. The stabilization of polymers is a broad scientific discipline comprising antioxidants, ${ }^{[7]}$ light $^{[8]}$ and heat stabilizers, ${ }^{[9]}$ just to mention the most important subfields, and it is not possible to discuss all of them here. The reader is referred to the indicated references or to comprehensive monographs. [10]

Our contributions to this field, with focus on the development of novel processing stabilizers for polyolefins, are described in the Sections 2-6.

\section{Stabilization of Polymers During Processing}

After polymerization, polyolefins are transformed into end-user articles by several processing or compounding steps in which they are molten at high temperatures $\left(200-300^{\circ} \mathrm{C}\right)$, and then extruded to make e.g. profiles, fibers, films, sheets, pipes, tubing or injected into molds to make a large variety of objects like kitchen utensils, containers, mechanical parts, garden furniture or car bumpers. Injection molding is the most common method of manufacturing plastic parts. However, polymer processing ${ }^{[11]}$ and extrusion are also the most damaging events in the life cycle of a polymer, because "it is not possible to envisage a more damaging process for polymers than the high shear mixer of the screw extruder" (quotation by G. Scott ${ }^{[12]}$ ).
A simplified picture of a polymer extruder is shown in Fig. 1, more information about extruders can be found on the websites of their manufacturers.

Polyolefins are materials that cannot be properly processed without adequate stabilization, and products made from them must be particularly well stabilized against thermo- and photooxidative degradation. Submitting polyolefins to extrusion at $200-300{ }^{\circ} \mathrm{C}$ results in chain scissions ${ }^{[13]}$ which generate carbon-centered (C-centered) radicals. The question, at which place along the chain does the macromolecule cleave, has been discussed ${ }^{[14]}$ very recently. As a consequence, the molecular weight of polypropylene (PP) decreases during the extrusion, whereas in polyethylene chain scissions and crosslinking via addition of macroradicals to the remaining vinyl groups, present from the polymerization process, may occur simultaneously as competitive reactions. ${ }^{[13 a]}$

Under processing conditions as they exist in an extruder very little oxygen is present, and the concentration ratio of $\mathrm{ROO}^{\bullet}$ to $\mathrm{R}^{\bullet}$ is less than 1 . This is significantly different ${ }^{[15]}$ from thermo-oxidative aging in air, where the concentration of peroxyl radicals (and hydroperoxides) is much greater than that of alkyl radicals $\left(\mathrm{ROO}^{\circ} / \mathrm{R}^{\bullet}>>1\right)$. It is important to note that alkyl radicals react at a diffusioncontrolled rate ${ }^{[16]}$ with oxygen dissolved in and diffusing into the polymer (reaction 2 , Scheme 1). The oldest approach for stabilization of polyolefins during extrusion used low molecular weight (MW) phenolic antioxidants (AO) like 2,6-di-t-butyl4-hydroxytoluene (BHT) and the like. These low MW products were found to be limited in their performance, especially for long term thermal stability after extrusion. They were replaced by the Martin Dexter (chemist at Geigy and later Ciba-Geigy)

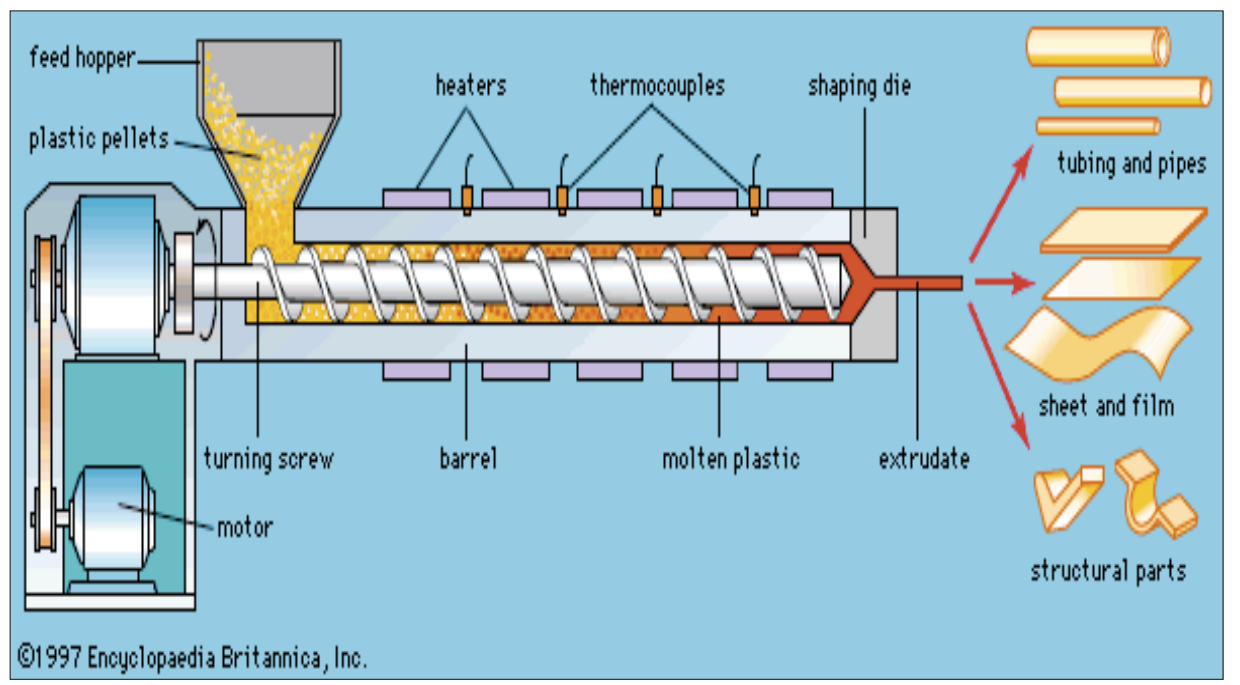

Fig. 1. Polymer extruder. By courtesy of Encyclopaedia Britannica, Inc., copyright 1997; used with permission. 
$\operatorname{Irganox}^{\circledR}$ line (e.g. 1, Scheme 2) of higher MW phenolic antioxidants in the late 1960s and early 1970s. ${ }^{[17]}$ In the early 1980s the phenolic AO's were combined with phosphite melt processing stabilizers (PS), e.g. Irgafos ${ }^{\circledR} 168(2$, Scheme 2$)$ to create ${ }^{[18]}$ the first AO/PS 'synergistic systems'.

The phenols are radical trapping (also called chain breaking or primary) antioxidants which scavenge oxygen-centered radicals produced by reactions $2,4,5$ and 8 (Scheme 1). Excellent reviews ${ }^{[7 a, 19]}$ of their mechanism of action are available. The preventive, also known as secondary, phosphite antioxidants reduce the hydroperoxides into alcohols, and thus prevent their cleavage into novel $\mathrm{O}$-centered radicals by reactions 4 and 5 . Scheme 2 shows an example of a typical phenolic $\mathbf{1}$ and phosphite antioxidant $\mathbf{2}$, including their most common, but by far not the only existing, commercial names. In the meantime, many analogues $^{[7 b, 10,20]}$ from different manufacturers with tailor-made physical properties (e.g. solubility, volatility, etc.) are on the market. For long-term stabilization of polymers during their service life the very important derivatives of 2,2,6,6-tetramethylpiperidine, also known as hindered amine light stabilizers (HALS), e.g. 3, and dialkyl thioethers, e.g. 4, are used. However, these stabilizers are not effective as processing stabilizers, and are therefore not discussed here.

Mixtures of classical phenolic ${ }^{[21]}$ and phosphite antioxidants do not trap the $\mathrm{C}$-centered radicals efficiently, and therefore do not inhibit the auto-oxidation of the polymer at the early stage of the alkyl radical formation (reaction 1 , Scheme 1); i.e. not as soon as the autoxidation starts. Furthermore, the continuously increasing performance criteria in the industry, such as increased processing temperatures (up to $300{ }^{\circ} \mathrm{C}$ ), increased residence times, or increased shear forces in the extruder, require even more active stabilization systems. Significant improvements were achieved in the early $1990 \mathrm{~s}$ with $N, N$-dioctadecyl hydroxylamine ${ }^{[22]} \mathbf{5}$ and Vitamin E 6, which are both better $\mathrm{H}$-donors than derivatives of 2,6-di-t-butylphenol. Good results are also achieved using monoacrylates of sterically hindered bisphenols, e.g. 7. The noteworthy stabilizing mechanism ${ }^{[23]}$ of 7 consists of C-radical trapping by the acrylate group, followed by fast $\mathrm{H}$ transfer from intramolecularly H-bonded free phenolic $\mathrm{OH}$ groups to afford a stable phenoxyl radical. Even though 5-7 represent important improvements, there still was a need for a more universal and powerful processing stabilizer.

It is important to keep in mind that the performance/price ratio of a novel antioxidant must be better than that of the state of the art compounds (see Scheme 2), or it

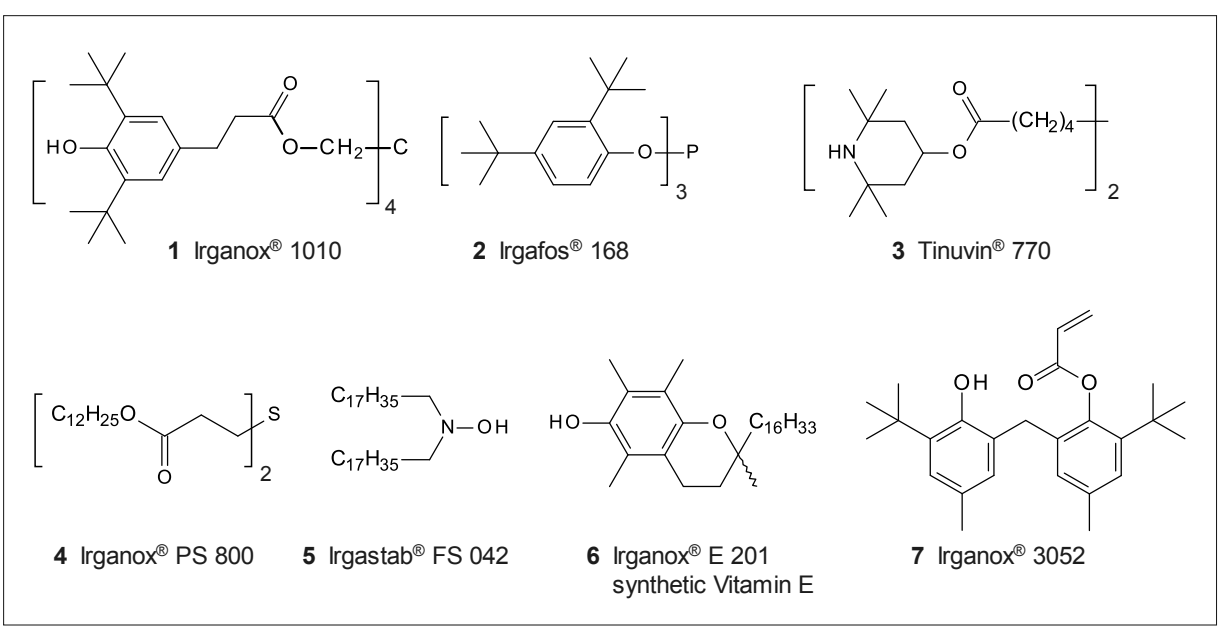

Scheme 2. Examples of commercial antioxidants for polymers.

must provide features not achievable with the latter. Industrial antioxidants are facing price erosion, e.g. copies of the excellent products $\mathbf{1}$ or $\mathbf{2}$ can be obtained for less than 10 US $\$ / \mathrm{kg}$. On the one side, this constrains the portfolio of reactions and starting materials available to a chemist working in this field, on the other side it is a formidable creativity challenge in his efforts to develop an improved, patentable, toxicologically safe and economically competitive product.

\section{Development of Novel 3-Aryl- benzofuranone Processing Stabilizers}

This chapter is a historic review of my first work when I joined the Ciba-Geigy additives research in 1987. One of my principal projects was to design, synthesize and evaluate a variety of novel potential processing stabilizers for polyolefins. Several compounds, for example the isoindolo[1,2- $b$ ]benzothiazol-11(4bH)one ${ }^{24]} 8$ and the $\alpha$-cyano-phenylacetate ester[25] 9 (Scheme 3) performed quite well. Both possess a weakly bound benzylic H-atom (red), and therefore act probably as chain breaking antioxidants. For example, the methyl ester analogue of 9 forms the corresponding C-radical and later its $\mathrm{C}-\mathrm{C}$ dimer when treated ${ }^{[26]}$ with 2,6-diphenyl-4-methoxyphenoxy radicals. The bond dissociation enthalpy (BDE) of the benzylic $\mathrm{C}-\mathrm{H}$ bond in $\mathbf{8}$ is only 76.2 $\mathrm{kcal} / \mathrm{mol}$ (my own calculation at G3MP2 level, 298K, 1 atm, gas phase), which makes it a better H-donor than 2,6-di-tbutyl-4-hydroxytoluene $\left(\mathrm{BDE}_{\mathrm{OH} \text { gas }}=79.6\right.$ $\mathrm{kcal} / \mathrm{mol}$ ).[27] Nevertheless, the development of $\mathbf{8}$ and $\mathbf{9}$ to commercialization was not pursued because of their unfavorable ancillary properties such as too high cost or toxicological concerns.

Therefore, quite rapidly, the focus was placed on the promising 3-aryl-ben- zofuran-2-ones. The result of this effort arrived in 1997 on the market under the trade name Irganox ${ }^{\circledR}$ HP-136 (see Section 4.). Hundreds of compounds were prepared and tested during this work, but only a brief synopsis can be described along the following lines. The first and simplest congener of this class, the 3-phenyl-benzofuran-2-on 10 (Scheme 4), was prepared in 1896 by the founder ${ }^{[28]}$ of the chemistry department of the University of Fribourg in Switzerland, Augustin Bistrzycki. His synthesis ${ }^{[29]}$ consisted of the condensation of phenol with mandelic acid in $73 \%$ $\mathrm{H}_{2} \mathrm{SO}_{4}$ and afforded $\mathbf{1 0}$ in a modest $22 \%$ yield. In 1977 Karafiloglou et al. ${ }^{[30]}$ reported the electron spin resonance (ESR) study of the blue persistent benzofuranyl radical 11, which is in thermal equilibrium with its dimer 12. The radical 11 was readily prepared via deprotonation of $\mathbf{1 0}$ and subsequent oxidation with iodine.

Inspired by Karafiloglou's work, in 1979 the Sandoz chemist Hans Hinsken and co-workers evaluated a series of 3-aryl-benzofuran-2-ones and 3-aryl-indolin-2-ones, as processing stabilizers for polymers, and observed the outstanding performance of the former. Despite the excellent activity of some compounds, e.g. the di-t-butyl derivative 13 , Sandoz only patented ${ }^{[31]}$ this discovery but did not commercialize these promising materials. When 3-aryl-benzofuran-2-ones became the focus at Ciba-Geigy in the late 1980s, it was clear that $\mathbf{1 3}$ is not a suitable candidate for development, mainly due to patent reasons and problems with scale-up. In fact, the synthesis of $\mathbf{1 3}$ con-

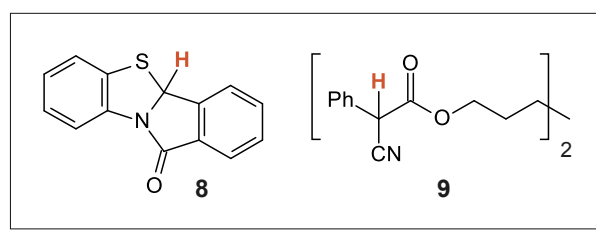

Scheme 3. Experimental processing stabilizers 8 and 9. 


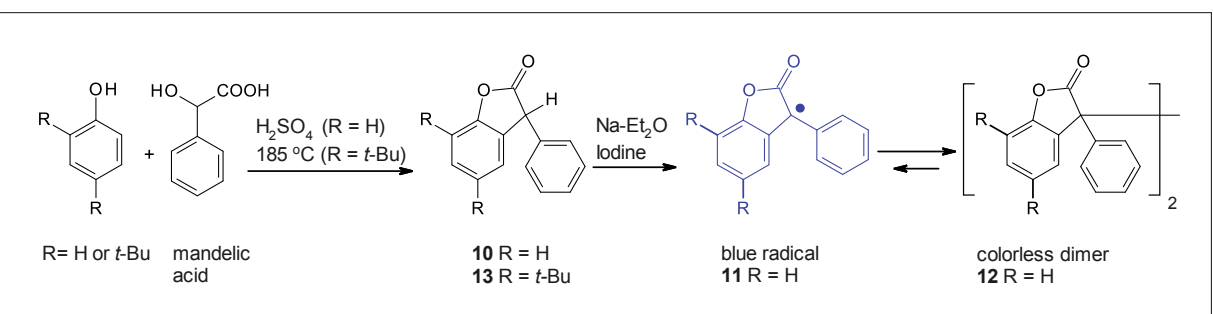

Scheme 4. 3-Phenyl-benzofuran-2-ones, their radicals and C-C dimers.

sists of heating 2,4-di-t-butyl-phenol with mandelic acid for $20 \mathrm{~h}$ at $185^{\circ} \mathrm{C}$ to afford 13 in only about $50-60 \%$ yield (no yield is indicated in ref. [31]). Nevertheless, 2,4-di$t$-butyl-phenol is an ideal starting material for a novel benzofuranone stabilizer: it is a cheap, multi-thousand ton commodity chemical which is also used for other antioxidants, e.g. 2. Furthermore, it is highly reactive towards electrophiles and its 4-t-butyl substituent prevents side-reactions at this position during the condensation with mandelic acid. Finally, the molecular weight of the novel stabilizer must not be too low to avoid issues such as volatilization or migration from the polymer. For this reason, phenols bearing smaller groups (e.g. Me, Et or 2-propyl) are less suitable.

Unfortunately, all trials to optimize the condensation reaction of 2,4-di-t-butylphenol with mandelic acid, or with mandelonitrile, failed. Of course, the reaction can be catalyzed ${ }^{[32]}$ with protic or Lewis acids, but these conditions also cause the cleavage of one or both $t$-butyl groups from the phenol. Consequently, we set out to develop more reactive, and cheaper alternatives to unsubstituted mandelic acid.

We speculated that mandelic acids bearing electron-donating substituents, e.g. alkoxy groups, in the 4-position would react with phenols easier than unsubstituted mandelic acid, because the benzylic carbenium ion intermediates $\mathbf{1 4 a}, \mathbf{b}$, which are supposed to alkylate the phenol to afford the open-chain intermediate 16, should be better stabilized (Scheme 5). However, the detailed mechanism is not known, and the intermediacy of the $\alpha$-lactone $\mathbf{1 5}$ may also be considered. In fact, unsubstituted $\mathbf{1 5}$ was proposed $\mathrm{d}^{[33]}$ as an intermediate during the thermal decomposition ${ }^{[34]}$ of mandelic acid into benzaldehyde and $\mathrm{CO}$, a reaction which may be co-responsible for the low yield of $\mathbf{1 3}$ in its classical thermal synthesis. The alternative pathway, in which the phenol would be first esterified by the mandelic acid and the $\mathrm{C}-\mathrm{C}$ bond and ring formation would follow, seems not very plausible. In fact, we could not observe any thermally induced cyclization of the ester of mandelic acid with 2,4-di-t-butylphenol to afford $\mathbf{1 3}$.

In a next step, the commercial and inexpensive 4-hydroxy-mandelic acid $\mathbf{1 7}$
(Scheme 6) was tested as an alternative to mandelic acid. Then, an efficient procedure for preparation of 3,5-dimethyl-4-hydroxy-mandelic acid (18) via reaction of glyoxylic acid with the cheap 2,6-dimethylphenol in aqueous $\mathrm{NaOH}$ was developed. To our delight, gentle heating of $\mathbf{1 7}$ or $\mathbf{1 8}$ with 2,4-di-t-butyl-phenol in acetic acid with only traces of $\mathrm{H}_{2} \mathrm{SO}_{4}$ catalyst afforded in $>90 \%$ yield the benzofuranones $\mathbf{1 9}$ and 20, respectively.

Later, numerous derivatives of $\mathbf{1 9}$ and 20 with alkylated, ${ }^{[35]}$ e.g. 21, carboxymethylated, ${ }^{[36]}$ e.g. 22, acylated, ${ }^{[37]}$ e.g. $\mathbf{2 3}$, or cycloalkylated, ${ }^{[38]}$ e.g. 25, phenolic $\mathrm{OH}$ group were prepared and tested. To complete the establishment of the structure-activity relationship, benzofuranones substituted with alkylthiomethy[ ${ }^{[39]}$ groups, e.g. 26, or bis-benzofuranones ${ }^{[40]}$ derived from bis-phenols, e.g. 27, were additionally prepared via the mandelic acid route. The compound best fulfilling the performance requirements was the 2-acetoxy-ethylether ${ }^{[41]} \mathbf{2 4}$, which in 1992 was considered

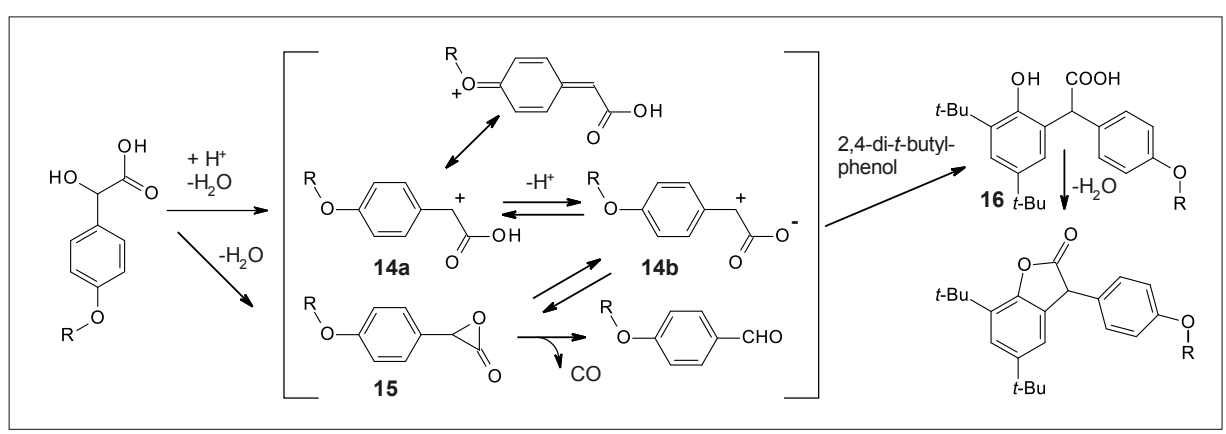

Scheme 5. Tentative mechanism of the condensation of mandelic acids with 2,4-di-t-butyl-phenol.

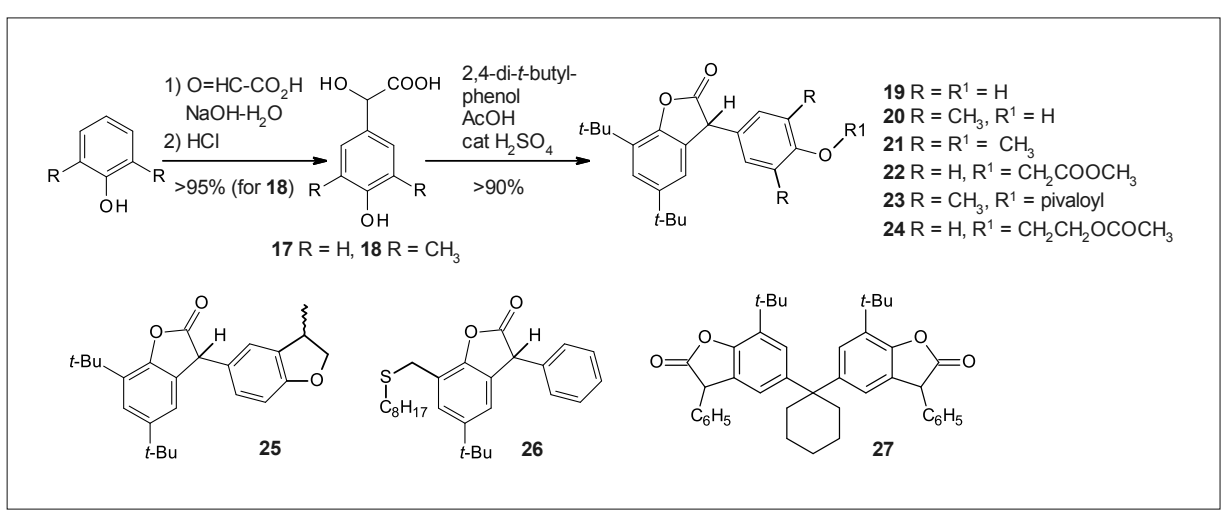

Scheme 6. Examples of experimental 3-aryl-benzofuranone processing stabilizers. for upscaling. However, shortly thereafter an even better compound and process was discovered!

\section{Development of Irganox ${ }^{\circledR} \mathrm{HP}-136$ Synthesis}

In 1992, we tried to prepare the 5,7-di$t$-butyl-3-hydroxy-2-benzofuranone 28 by reaction of glyoxylic acid with 2,4-di-t-butyl-phenol and traces of $p$-toluene sulfonic acid in refluxing toluene (Scheme 7). The desired 28 was indeed obtained in $>95 \%$ yield, however, a small amount of a side product 29 was also formed. Obviously, 28 performed a Friedel-Crafts alkylation of toluene to afford the $p$-tolyl benzofuranone 29, albeit in trace amounts only! Realizing this, the conditions and scope of this novel reaction were intensively investigated. A solid, acidic earth catalyst, easily removed by filtration after the reaction, was identified as an ideal catalyst for the alkylation of electron-rich aromates with 28. Xylenes at their boiling point showed optimal reactivity towards $\mathbf{2 8}$. Only one isomer, 32, is obtained with $p$-xylene, however, the $\mathrm{CH}_{3}$ group at the 2'-position lowers its activity as a processing stabilizer (see Section 5). Even less active are 2',6'-di-substituted derivatives, e.g. 33. Therefore, the reaction product of $\mathbf{2 8}$ with $o$-xylene was selected for scale-up, and was later commercialized under the trade name $\operatorname{Irganox}^{\circledR}$ HP-136 (HP stands for High Performance). The proprietary ${ }^{[42]}$ one pot synthesis of the lat- 
ter uses $o$-xylene as solvent and reagent at the same time, and the only side product of the synthesis is water!

Irganox ${ }^{\circledR} \mathrm{HP}-136$ is a mixture consisting of about $90 \%$ of the main isomer $\mathbf{3 0}$ and $10 \%$ of the less active isomer 31. One should note that in the academic literature often only $\mathbf{3 0}$ is given, incorrectly, as the structure of Irganox ${ }^{\circledR}$ HP-136.

The synthesis according to Scheme 7 works well only with electron-rich phenols like 2,4-di-t-butylphenol and activated aromates. Alkylation of benzene with $\mathbf{2 8}$ to afford $\mathbf{1 3}$ is also possible, however, a stoichiometric amount of $\mathrm{AlCl}_{3}$ instead of an acidic earth catalyst has to be used, ${ }^{[42 a]}$ which makes this synthesis less attractive. Benzofuranones bearing electron-withdrawing groups in their 3-aryl substituents are not accessible via this method. For such compounds, we have developed an alternative synthesis. ${ }^{[43]}$ Its key step is the palladium-catalyzed carbonylation of $o$-quinone methides which are generated from readily accessible Mannich bases. For instance, the Mannich base 34 afforded the cyanosubstituted benzofuranone 36, upon carbonylation of the in situ formed $o$-quinone methide 35 (Scheme 8). Carbonylative synthesis of naphthofuranones, ${ }^{[44]}$ and very recently, of benzofuran-2-ones from phenols and aldehydes with formic acid as the $\mathrm{CO}$ source, including some discussion of the carbonylation mechanism, has been published. ${ }^{[45]}$

Unfortunately, the activity of $\mathbf{3 6}$, and other benzofuranones substituted with electron-withdrawing groups $\left(\mathrm{CF}_{3}\right.$, COOR), as processing stabilizers, was not better than that of $\operatorname{Irganox}^{\circledR}$ HP-136. The latter can also be made ${ }^{[46]}$ by the carbonylation method, however, its synthesis according to Scheme 7 is economically more attractive.

Another access to 3-aryl-benzofuranones from Mannich bases via the $o$ quinone methide intermediates was described[47] by our colleagues Gerster and Reto. Their approach uses addition of cyanide to $o$-quinone methides, followed by cyclization and hydrolysis of the intermediate 3-amino-benzofuranes.

\section{Irganox ${ }^{\circledR}$ HP-136 Mechanism}

The outstanding properties of 3-arylbenzofuran-2-ones as processing stabilizers were recognized already by the Sandoz chemist Hans Hinsken and coworkers ${ }^{[31]}$ in 1980. During our development of Irganox ${ }^{\circledR}$ HP-136 (onwards referred to as HP-136), an empirical relationship between the structure of 3-aryl-benzofuran-2-ones and the stabilizer activity, and important properties such as the undesired discoloration of the polymer, was established. Fortunately,

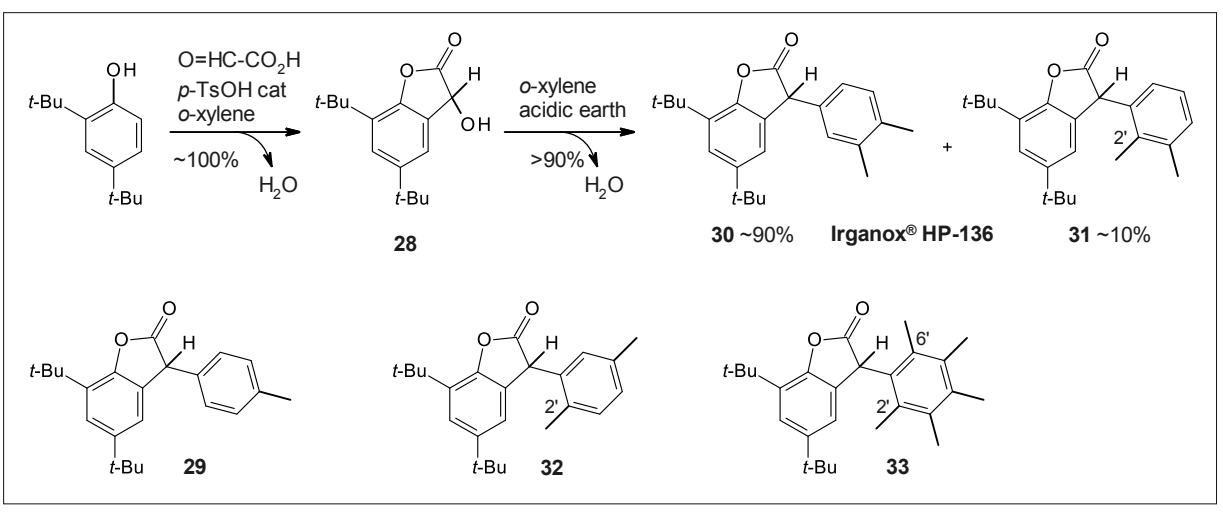

Scheme 7. Synthesis of Irganox ${ }^{\circledR} \mathrm{HP}-136$.

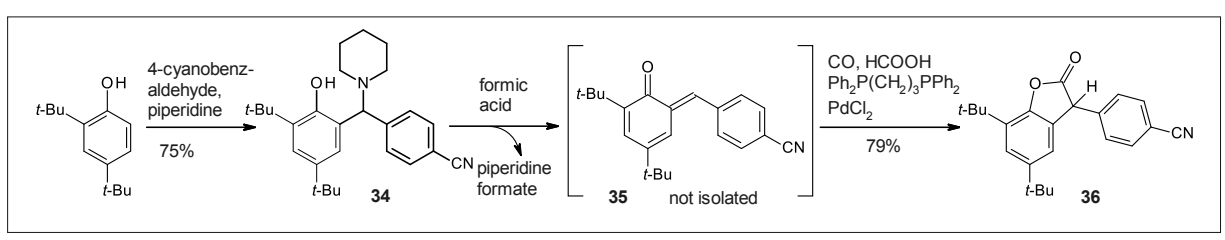

Scheme 8. Synthesis of benzofuranones by carbonylation.

shortly after its commercialization in 1997 , HP-136 triggered considerable interest in academia, and a deep understanding of its high activity, based on kinetic, thermodynamic and computational data was then developed by several ${ }^{[48]}$ groups. The reader is referred to the review ${ }^{[7]}$ by Ingold and Pratt for a detailed summary of these results. Therefore, only the most salient features are discussed here (Scheme 9). One should keep in mind that practically all investigations were performed on the main isomer 30 of HP-136. Nevertheless, the conclusions are also valid for the minor isomer 31. HP-136 possesses a weakly bound benzylic H-atom (red) which is donated to peroxyl, alkoxy and $\mathrm{OH}$ radicals generated during auto-oxidation (Scheme 1, reactions 2,4,5,8). Xiao-Qing Zhu and coworkers ${ }^{[48 \mathrm{~d}]}$ measured the Gibbs freeenergy change on homolysis of a series of 3 -aryl-benzofuran-2-ones into $\mathrm{H}^{\bullet}$ atom and the related aryl-benzofuranonyl radicals in DMSO at $298 \mathrm{~K}$. The value of $68.2 \mathrm{kcal} /$ mol obtained for the homolysis $\mathbf{3 0} \rightarrow \mathrm{H}^{\bullet}+$ 38 is significantly lower than those for the homolysis of the phenolic groups $\mathrm{ArOH} \rightarrow$ $\mathrm{H}^{\bullet}+\mathrm{ArO}{ }^{\bullet}$ in, e.g. $\alpha$-tocopherol $(74.3 \mathrm{kcal} /$ mol) or 2,6-di-t-butyl-4-methyl-phenol (BHT, $78.3 \mathrm{kcal} / \mathrm{mol}$ ). However, it seems that it is not the lactone $\mathbf{3 0}$ which is the actual $\mathrm{H}^{\bullet}$-donor, but rather its enol tautomer 37. It is well known that $\mathrm{O}$-centered radicals abstract $\mathrm{H}$-atoms from $\mathrm{O}-\mathrm{H}$ donor groups significantly more rapidly than from a C-H donor of comparable bond strength, largely because of prior $\mathrm{H}$-bond formation between the reactants and $\mathrm{H}$-atom transfer by the proton-coupled electron transfer mechanism, see the discussion in ref. [7a]. In fact, Scaiano and coworkers ${ }^{[48 \mathrm{f}, \mathrm{j}]}$ provided strong evidence that the $\mathrm{H}$-atom ab- straction by $t$-butoxyl (and ROO*) occurs primarily from the enol $\mathbf{3 7}$, even at a low enol content ${ }^{[48 \mathrm{j}]}$ of about $0.5 \%$ in non-polar solvents (hexane) at room temperature.

In this respect, HP-136 behaves similarly to many phenolic antioxidants where the $\mathrm{H}^{\bullet}$-donor is the $\mathrm{OH}$ group. One must note, however, that the arguments of Scaiano in favor of the enol $\mathbf{3 7}$ as the actual $\mathrm{H}^{\bullet}$-donor were questioned by $\mathrm{Nau}$ and coworkers ${ }^{[48 i]}$ and Xiao-Qing Zhu and coworkers, ${ }^{[48 \mathrm{~d}]}$ mainly because of the low equilibrium concentration of 37. Despite this, once the $\mathrm{H}^{\bullet}$-transfer has occurred, the blue radical $\mathbf{3 8}$ behaves predominantly as a $\mathrm{C}$-centered radical with unique properties. On the one side, $\mathbf{3 8}$ dimerizes reversibly into the head-to-head dimer ${ }^{[48 \mathrm{k}]}$ meso-39, possessing rather weak $\left(\Delta \mathrm{H}_{\text {diss }}=\right.$ $22.8 \mathrm{kcal} / \mathrm{mol})$ and long $(0.1586 \mathrm{~nm}$, data from X-ray structure) central $\mathrm{C}-\mathrm{C}$ bond. The head-to-head coupling of arylbenzofuranyl radicals is their preferred mode of dimerization, even though the possibility of unsymmetrical head-to-tail coupling of radical 11 (Scheme 4), similar to that of the triphenylmethyl radical[49] $\mathrm{Ph}_{3} \mathrm{C}^{\bullet}$, was also reported. ${ }^{[50]}$ Most importantly, 38 has very low reactivity toward oxygen, in contrast to the vast majority of $\mathrm{C}$-centered radicals, which rapidly react ${ }^{[16]}$ with oxygen leading to peroxyl radicals which then propagate the oxidative chain (Scheme 1, reaction 2). Scaiano and coworkers ${ }^{[48 r]}$ found that $\mathbf{3 8}$ reacts with oxygen to afford the peroxyl radical 40 over 10000 times more slowly than a typical C-centered diphenyl methyl radical $\mathrm{Ph}_{2} \mathrm{CH}^{*}$ ! Furthermore, this reaction is reversible, and the equilibrium strongly favors 38 as compared to the analogous reversible reaction of triphenylmethyl radical $\mathrm{Ph}_{3} \mathrm{C}^{\bullet}$ with $\mathrm{O}_{2}$ leading to $\mathrm{Ph}_{3} \mathrm{COO}{ }^{\bullet}$ and 


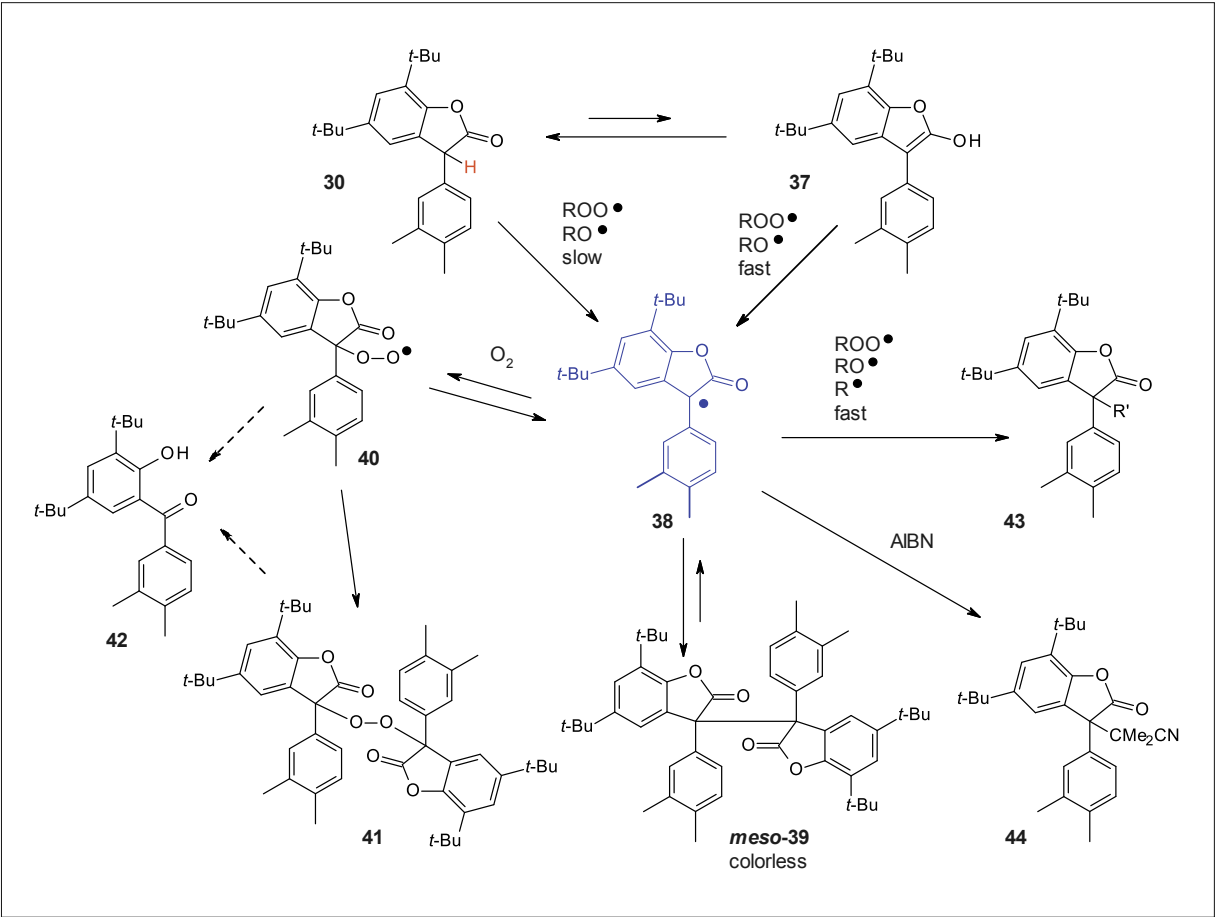

Scheme 9. Mechanism of Irganox ${ }^{\circledR}$ HP-136.

finally to trityl peroxide ${ }^{[51]} \mathrm{Ph}_{3} \mathrm{COOCPh}$ The peroxide 41 was not yet reported, however, it may slowly form during long exposure of $\mathbf{3 8}$ or $\mathbf{3 9}$ to $\mathrm{O}_{2}$. Analogous peroxides from the radical $\mathbf{1 1}$ (Scheme 4) and from 3-phenyl-naphthofuran-2-one are known. [52]

The low reactivity of $\mathbf{3 8}$ towards $\mathrm{O}_{2}$ is due to several synergistic effects. The $\mathrm{X}$-ray structure ${ }^{[48 r]}$ of $\mathbf{3 0}$ shows that the lactone ring forces the coplanarity of the attached aromatic ring, thus maximizing delocalization of the unpaired electron onto this ring. This makes the two rings in 38 more effective than the three rings in $\mathrm{Ph}_{3} \mathrm{C}^{\bullet}$ in providing resonance stabilization. Furthermore, density functional calculation showed[48q] significant spin delocalization on the carbonyl oxygen. Moreover, it is likely that the electron-withdrawing nature of the carbonyl group diminishes the reactivity of $\mathbf{3 8}$ with the electrophilic

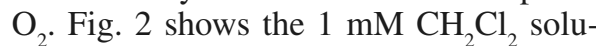
tions of the radical dimers (both colorless in solid state) from the major (30) and minor (31) isomer of Irganox ${ }^{\circledR}$ HP-136 after $1 \mathrm{~h}$ at room temperature under air.

The central $\mathrm{C}-\mathrm{C}$ bond in the dimer from 31 (right) is even weaker than in $\mathbf{3 9}$ due to its steric destabilization by the 2'$\mathrm{CH}_{3}$ group. Consequently, the concentration of the corresponding radical at room temperature is higher than in the case of the 39/38 couple, and the purple color of the radical is nicely seen. Under the same conditions, the color of the radical 38, present in lower concentration, is not perceptible to the naked eye. The benzofuranyl radicals are in most cases purple constant ${ }^{[48 \mathrm{~h}]}$ for reaction of $\mathbf{3 8}$ with peroxyl radicals is $\sim 10^{8} \mathrm{M}^{-1} \mathrm{~s}^{-1}$, which makes it a more efficient peroxyl radical trap than Vitamin E (6)! Most importantly, 38 reacts rapidly also with $\mathrm{C}$-centered radicals, unfortunately, no quantitative kinetic data are known to the author. In fact, the dimerization of $\mathbf{3 8}$ is already such a reaction, and refluxing 39 with 2 equivalents of azo-bisisobutyronitrile (AIBN) in benzene afforded the cross-coupled product $\mathbf{4 4}$ in $\mathbf{9 8 \%}$ yield (P. Nesvadba, unpublished results). Moreover, the so-called Fischer-Ingold persistent-radical effect ${ }^{[48 g, 53]}$ should favor the cross-coupling of $\mathbf{3 8}$ with other radicals to afford adducts $\mathbf{4 3}$, and therefore also with C-centered radicals existing under oxygen-depleted conditions during the polymer extrusion (Scheme 1, reaction 1).

As mentioned in Section 4, we have observed that the minor isomer $\mathbf{3 1}$ of HP136 is less active than the major isomer $\mathbf{3 0}$, probably due to the steric shielding of the radical center by the 2'- $\mathrm{CH}_{3}$ group. Later, Zhong Xin and coworkers ${ }^{[48 e, 54]}$ measured rates of $\mathrm{H}$-abstraction by $t$-butoxy radicals from 3-aryl benzofuranones bearing a 2'$\mathrm{CH}_{3}$ group, and found them to be also worse $\mathrm{H}$-donors then those with a $\mathrm{CH}_{3}$ group in the 3'- or 4'-position. Interestingly, Xin and coworkers ${ }^{[48 \mathrm{~b}]}$ reported that 3-phenylbenzofuranones having an $\mathrm{OH}$ group in the 2'-position of the phenyl ring were better processing stabilizers for polypropylene than those having $\mathrm{H}$ or $\mathrm{CH}_{3}$ in the same position. They explained this by an intramolecular hydrogen bond between radicals (Scheme 9). The estimated rate

to blue, however substitution can change their color. For instance, the radical derived from 13 bearing a $\left(\mathrm{CH}_{3}\right)_{2} \mathrm{~N}$ - group in the $p$-position of its 3-phenyl substituen is deep green (P. Nesvadba, unpublished result).

In contrast to its inertness to oxygen,
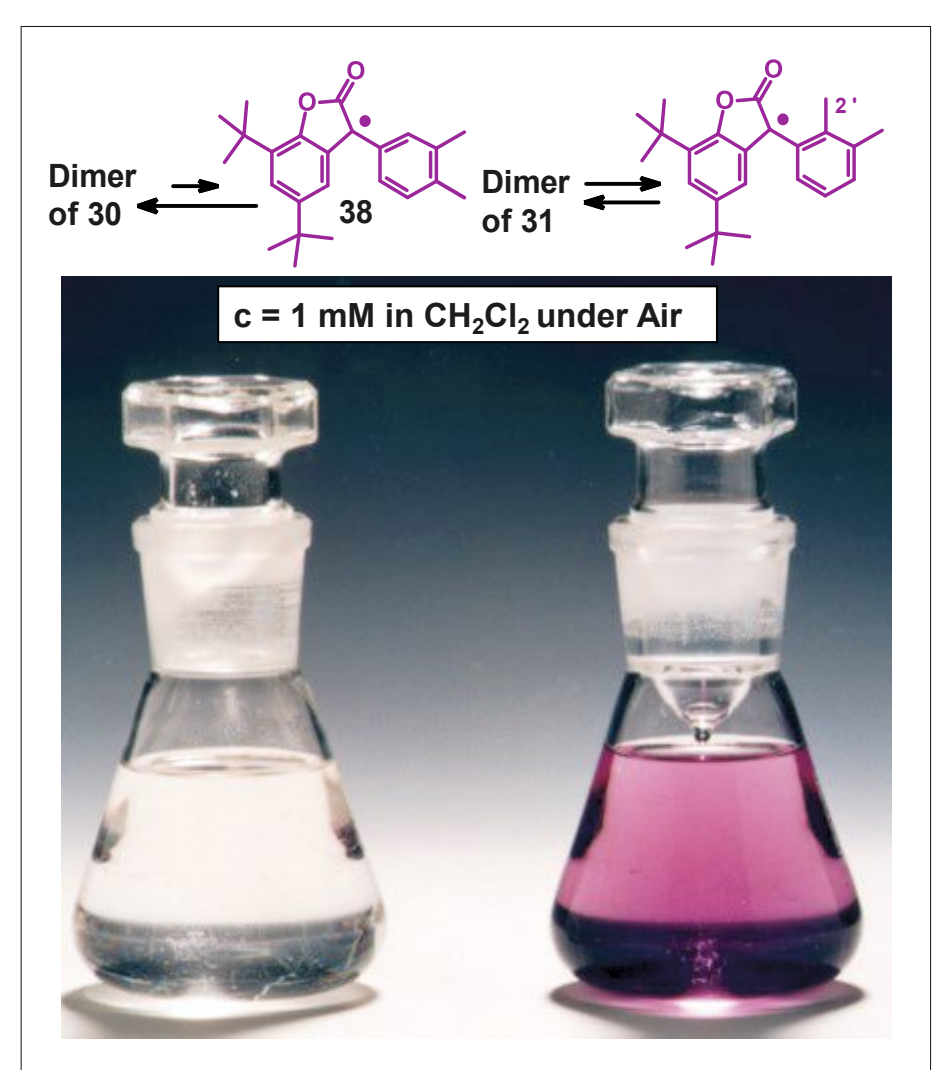

Fig. 2. Solutions of the dimers of the major (30, left) and minor (31, right) isomer of Irganox ${ }^{\circledR} \mathrm{HP}-136$ in $\mathrm{CH}_{2} \mathrm{Cl}_{2}$ under air at room temperature. 
the benzylic hydrogen at position 3 and the oxygen of the 2 'OH group which would increase the $\mathrm{H}$-donation ability of the $\mathrm{OH}$ group.

Recently, Rychly[48a] and coworkers observed that HP-136 is an excellent UV stabilizer of polypropylene films. This, at first glance, surprising result was explained by the oxidative degradation of HP-136 in the polymer film via $\mathbf{3 8}$ and $\mathbf{4 0}$ (possibly also 41) into the hydroxy benzophenone 42. In fact, hydroxy benzophenones are well known ${ }^{[8 a, d]}$ UV-light absorbers. Some time ago, we developed ${ }^{[55]}$ a preparative oxidation of 30 into 42 using alkaline $\mathrm{K}_{3} \mathrm{Fe}(\mathrm{CN})_{6}$, but of course, the mechanism of this reaction is different.

The dimer 39 is in several respects a remarkable compound. Above all, its antioxidant activity increases with temperature due to the increase in the steady state concentration of 38. During Irganox ${ }^{\circledR} \mathrm{HP}$ 136 development, we have also observed that dimers like 39, and analogues, show comparable performance to HP-136 as processing stabilizers. Consequently, these structures were included in our patents, e.g. ref. [41], however, the additional step needed for their synthesis was not justifiable from the economical point of view. Nevertheless, in 2005 Scaiano filed a new patent ${ }^{[56]}$ claiming the use of $\mathbf{3 9}$ and dimers of other radicals, e.g. 64 (Scheme 16, below), as "thermally modulated antioxidants." Possibly, these dimers may find use as antioxidants in polar environments. In fact, their effectiveness is not negatively affected[48f] by hydrogen bond accepting solvents where the classical antioxidants that donate an $\mathrm{H}$-atom to $\mathrm{ROO}^{\circ}$ from an $\mathrm{OH}$ group are less active. A brief review of these "radically different antioxidants" ${ }^{[48 \mathrm{~h}]}$ was written by Korth. ${ }^{[57]}$

In contrast to the 3-aryl-benzofuranyl radicals, the isomeric 3-aryl-iso-benzofuranyl radicals react with oxygen very rapidly. We have shown ${ }^{[58]}$ that the intensively red colored, sterically hindered 3-mesityl-iso-benzofuranyl radicals $\mathbf{4 5}$ form a head-to-head dimer $\mathbf{4 6}$ with an even weaker central $\mathrm{C}-\mathrm{C}$ bond $\left(\Delta \mathrm{H}_{\text {diss }}=20 \mathrm{kcal} /\right.$ mol in toluene) than 39 (Scheme 10). The radicals $\mathbf{4 5}$ are very persistent under argon, but disappear within a few seconds if air is admitted, probably forming the corresponding peroxide. Later, Scaiano and coworkers ${ }^{[48 \mathrm{~m}]}$ found that 3-phenyl-isobenzofuranone reacts at $30{ }^{\circ} \mathrm{C}$ in benzene about half as fast with cumyloxy radicals than 30, but its radical is rapidly quenched by oxygen with a rate constant of $7.2 \times 10^{8}$ $\mathrm{M}^{-1} \mathrm{~s}^{-1}$. 3-Aryl-iso-benzofuranones were reported as stabilizers in the patent literature, ${ }^{[59]}$ however, they are definitely less active than the 3-aryl-benzofuranones, and no commercial development is known to the author.

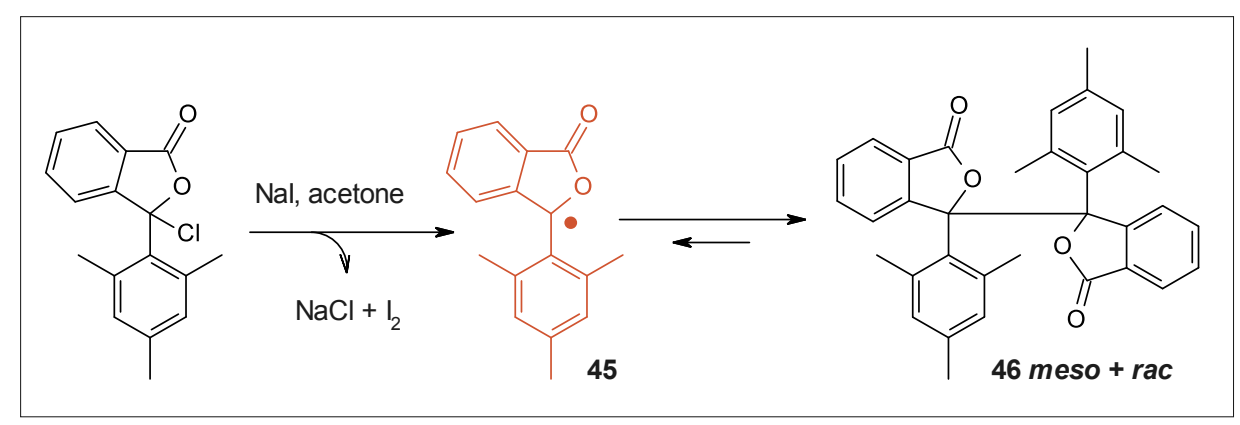

Scheme 10. Persistent 3-mesityl-iso-benzofuranyl radical 45 and its dimer 46.

\section{Application of Irganox ${ }^{\circledR} \mathrm{HP}-136$ - Past, Present and Future}

Irganox $^{\circledR}$ HP-136 (further HP-136) was commercialized in 1997. It was used mainly as a booster for mixtures of phenolic and phosphites antioxidants called B-blends. The enhanced, synergetic HPblends, for example Irganox ${ }^{\circledR}$ HP-2225 blend consisting of $42.5 \%$ of $1,42.5 \%$ of 2 and 15\% HP-136, showed significantly improved performance over the original binary blends as processing stabilizers for polyolefines. Several detailed reports ${ }^{[20,60]}$ on their outstanding performance are available. The migration and solubility ${ }^{[480]}$ of HP-136 in polypropylene (PP) and its efficiency as long term ${ }^{[48 \mathrm{p}]}$ antioxidant in PP at $180{ }^{\circ} \mathrm{C}$ was investigated by Greci and coworkers. HP-136 set new standards for polymer stabilization and became rapidly a major commercial success. When cumulative sales of HP-136 reached 1000 tons, a more detailed toxicological study of HP136 was requested in view of its steadily increasing production. Completely unexpected, the study showed that HP-136 fed in very high dosages has negative effects in selected reprotoxicity studies. Ciba, as a highly responsible company then preferred to retire the product from the market, rather than to take the, probably very low, risk which the customers might have been faced.

Does this mean the end of aryl-benzofuranones, sometimes also called lactones, as highly efficient stabilizers for polymers, where Irgano ${ }^{\circledR}$ HP-136 played the groundbreaking role? The answer is a clear no. In fact, not every aryl-benzofuranone is po- tentially reprotoxic, and in the meantime there are already two follow-up lactone products on the market, 47 commercialized by Chitec Ltd. under the name[61] Revonox $^{\circledR} 501$, and 48 which is part of a BASF stabilizer ${ }^{[62]}$ Irgastab ${ }^{\circledR}$ PUR 68 used to prevent scorching (thermally induced discoloration) during production of polyurethane foams. The key step in the synthesis of both $\mathbf{4 7}$ and $\mathbf{4 8}$ is the condensation of glyoxylic acid with $p$-substituted phenols as in our synthesis of HP-136 (Scheme 7), however the $o$-xylene is replaced by the second equivalent phenol, and its higher reactivity allows to perform both steps with a catalytic amount of a strong acid as a 'one pot' reaction (Scheme 11).

Furthermore, the recent patent literature suggests that novel lactone stabilizers may appear in the near future.

\section{Benzofuranyl Radicals Beyond Stabilization}

The weak central $\mathrm{C}-\mathrm{C}$ bond in dimers of aryl-benzofuranyl radicals and the inertness of the latter towards $\mathrm{O}_{2}$ offer numerous possibilities beyond antioxidants. Otsuka and coworkers prepared from the hydroxyphenyl benzofuranone 19 the dimeric diol 49 and tetraol 50 mechanophore crosslinkers (Scheme 12). Incorporation of 50 into a polyurethane (PUR) network generated self-healing[63] or exchangeable ${ }^{[64]}$ PUR gels where $\mathbf{5 0}$ functioned as a reversible crosslinker. Almost complete recovery of the mechanical properties was observed [65] after heating the PUR specimens with incorporated 49 crosslinkers

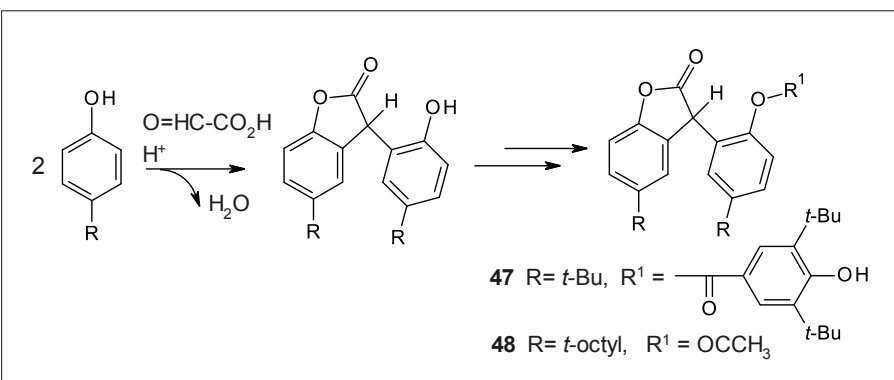

Scheme 11. Current commercial arylbenzofuranone stabilizers. 
at $50{ }^{\circ} \mathrm{C}$ for $12 \mathrm{~h}$ under air. Repeated mechanical scission and recombination of the mechanophore 49 incorporated in segmented polyurethane elastomers was demonstrated ${ }^{[66]}$ by their blue coloration and simultaneous fading.

Furthermore, 49 was used to modify the surface of cellulose nanocrystals (CNC). The latter could be used to effectively reinforce a self-healable polymer containing similar dynamic covalent linkages through the formation of reversible covalent bonds between the CNC surfaces and the polymer matrix, while the nanocomposite retained the ability to self-heal. ${ }^{[67]}$ Similarly, poly(ethylene glycol)-block-poly(aspartic acid) amphiphilic micelles were reversibly crosslinked ${ }^{[68]}$ via attachment of the 2-hydroxyethyl ether of $\mathbf{1 9}$ and ensuing oxidation to form the bis-arylbenzofuranyl crosslinks.

Functionalization of $\mathbf{4 9}$ and $\mathbf{5 0}$ with 3 -isocyanato-trimethoxypropylsilane and following sol-gel reaction afforded mechanochromic silica ${ }^{[69]}$ networks. Very remarkable is that the PUR gel 51, crosslinked with $\mathbf{5 0}$ and swollen with 1,4-dioxane, turns ${ }^{[70]}$ blue after its cooling to minus $195{ }^{\circ} \mathrm{C}$ (Fig. 3). The formation of the blue color indicates that freezing of the gel and the subsequent solvent crystallization generates mechanical forces along the polymer chains which are strong enough to dissociate the $\mathrm{C}-\mathrm{C}$ bonds of the benzofuranone dimer crosslinker into blue radicals.
Recent computational study[71] suggested, that out of the three possible diastereomers of $\mathbf{5 0}$ the meso form will be formed preferably through $\mathrm{C}-\mathrm{C}$ coupling of the related radicals. Furthermore, the reaction of these radicals with oxygen was found energetically disfavored (see also Section 5). A short while ago, Otsuka and coworkers ${ }^{[72]}$ prepared polystyrenes containing tetraaryl succinonitrile ${ }^{[73]}$ or diaryl bibenzothiophenonyl[72] mechanophores which form upon cleavage pink or green radicals, respectively. Mixing these polymers with polystyrene containing the mechanophore 49 in an appropriate ratio allows to prepare polymer blends generating almost any color when exposed to mechanical stress or heat. The most recent review ${ }^{[70 b]}$ of the unique chemistry of polymers containing diaryl-bibenzofuranone dynamic carbon-carbon covalent linkages has been published by Imato and Otsuka.

\section{Serendipidous Discovery of a Novel Synthesis of Isoxindigos - Lactone Orange and Cool Black}

"Serendipity is not the product of patience; it's the product of action." (Audrey Moralez).

During the work on the synthesis of Irganox $^{\circledR}$ HP-136 (Scheme 7), red colored reaction mixtures were sometimes obtained. Structure elucidation of the iso-

Scheme 12. Reversible arylbenzofuranone dimer crosslinkers.
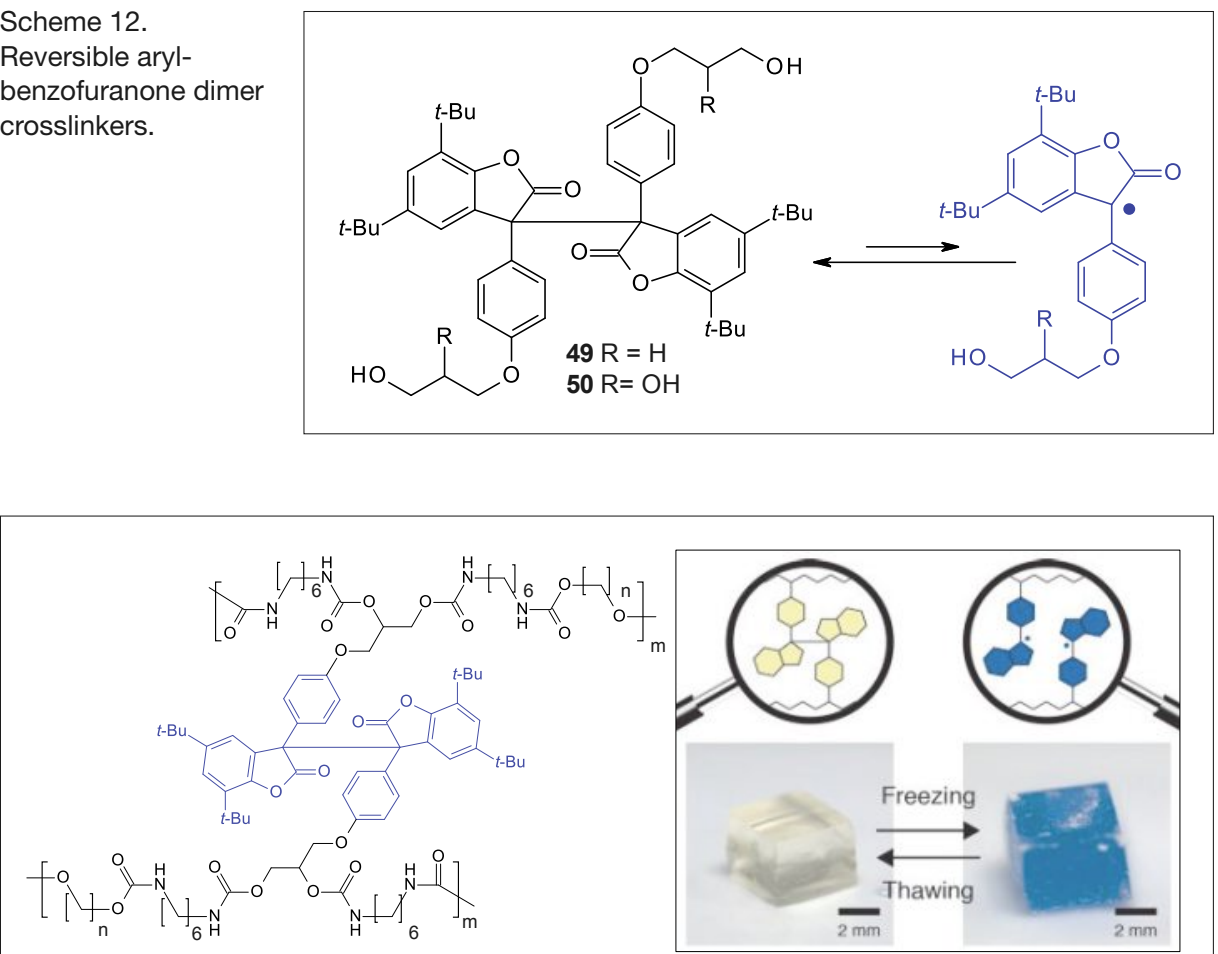

PUR polymer $\mathbf{5 1}$ crosslinked with $\mathbf{5 0}$

Gel of the polymer 51 swollen with 1,4-dioxane before and after freezing to liquid $\mathrm{N}_{2}$ temperature

Fig. 3. Cleavage of polymeric chains upon freezing of the gel of 51. Photograph reproduced with permission from ref. [70a], copyright Wiley-VCH 2015. lated red dye identified it as the bright red isoxindigo 55 (Scheme 13 and Fig. 4). A complex synthesis of this particular isoxindigo was described ${ }^{[74]}$ for the first time in 1982. Later, Sartori and coworkers ${ }^{[75]}$ reported a synthesis of isoxindigos (but not of 55) feasible on a small scale. It consisted of reaction of potassium phenolates with a stoichiometric amount of $\mathrm{AlCl}_{3}$, followed by alkylation of the dichloroaluminium phenolate with trichloroacetaldehyde and ensuing cyclization-dehydrochlorinationdimerization with $\mathrm{Al}_{2} \mathrm{O}_{3}$ in boiling decalin. Before this time, isoxindigos were rather a curiosity. ${ }^{[76]}$ In view of this, we felt that our observation may be a starting point for the development of a simple, scalable synthesis of isoxindigos. Extensive experimentation resulted in a synthesis depicted in Scheme 13. It consists of chlorination of 3-hydroxy-benzofuran-2-ones with $\mathrm{SOCl}_{2}$, followed by dehydrochlorination-dimerization with tertiary amines. This novel synthesis ${ }^{[77]}$ of isoxindigos works best with electron-rich phenols which react readily with glyoxylic acid to give the starting 3-hydroxy-benzofuran-2-ones, e.g. 28. Its tentative mechanism involves the dehydrochlorination of the 3-chloro-benzofuranone $\mathbf{5 2}$ to afford the carbene $\mathbf{5 3}$ and its dimerization to yield 55. Similar 5,7-di$t$-butyl-2,2-diethoxy-3H-benzofuranyl carbene and its dimerization, followed by hydrolysis leading to $\mathbf{5 5}$ was reported ${ }^{[78]}$ by Saalfrank, Böhme and coworkers. However, a later work by Kresge, Wirz and coworkers ${ }^{[79]}$ showed that the carbene derived from 3-diazo-benzofuran-2-one is very short-lived and undergoes rapid ring opening to 6-(oxoethenylidene)-2,4-cyclohexadien-1-one, the actual species dimerizing to the (unsubstituted) isoxindigo. In view of this, the intermediacy of the cumulenone $\mathbf{5 4}$ may also be considered.

The synthesis of isoxindigo 55 was scaled up to ton scale, and $\mathbf{5 5}$ was briefly on the market under the trade name Orace ${ }^{\circledR}$ Orange LGP. ${ }^{[80]}$ It was used as a polymer soluble, highly thermostable and lightfast colorant for styrene polymers. Unfortunately, the marketing of the product had to be discontinued, due to formation of tiny impurities with negative toxicological properties, generated during the production process. The isoxindigo dyes show a remarkably strong color vs substitution dependence. Thus, the unsubstituted isoxindigo is yellow, $\mathbf{5 5}$ is deep red (Fig. 4) and the 5,5'-dimethoxy-7,7'-di-t-butylisoxindigo is virtually black in solid phase and purple in solution. The ready availability of isoxindigos due to our novel synthesis also greatly simplified the access to the isomeric dibenzonaphthyrones. When treated with bases, isoxindigos rearrange into the isomeric, hypsochromically shifted dibenzonaphthyrones. ${ }^{[74,76 a, 81]}$ For 


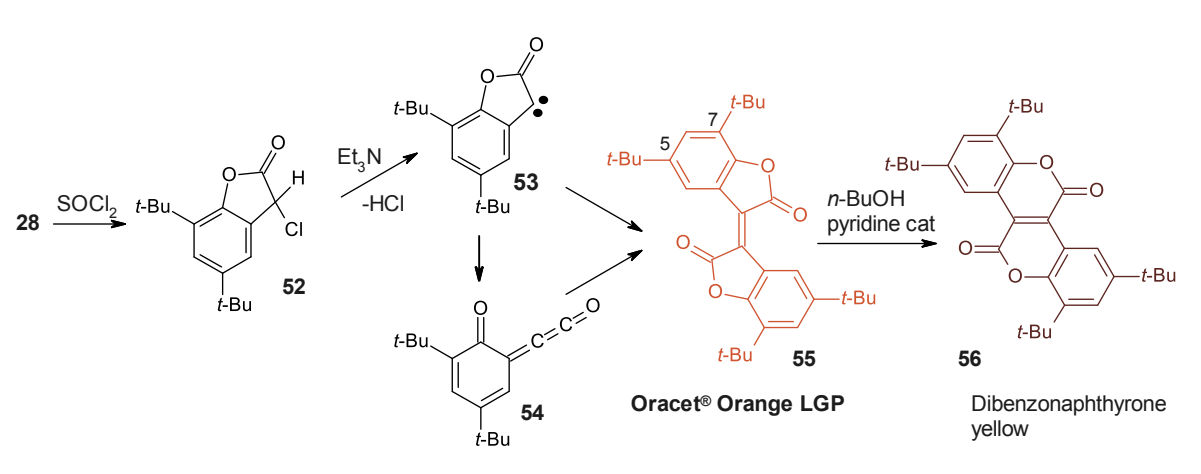

Scheme 13. Synthesis of isoxindigo 55 and dibenzonaphthyrone 56.

Fig. 4. Isoxindigo (Oracet ${ }^{\circledR}$ Orange LGP) (55) and Cool black (Irgaphor $^{\circledR}$ S100 Black CF) (58).
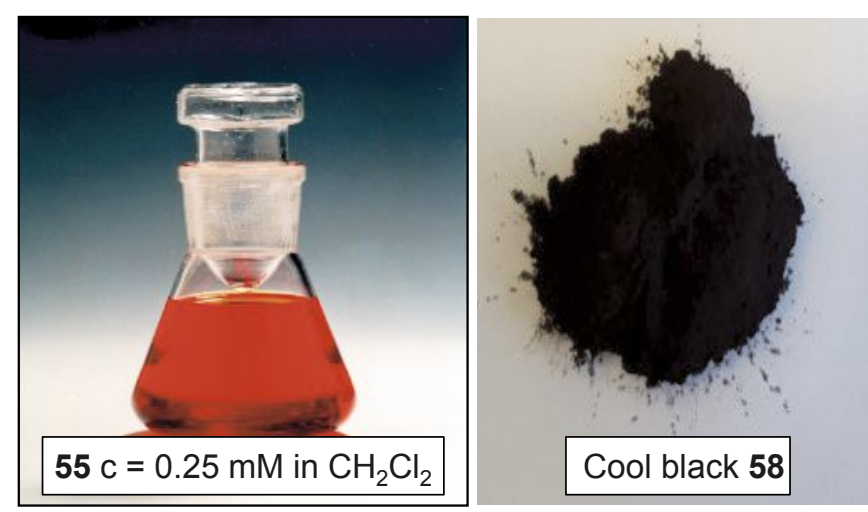

example, the red $\mathbf{5 5}$ afforded the goldenyellow dibenzonaphthyrone 56. We have prepared a series of dibenzonaphthyrones and evaluated them as polymer-soluble colorants $^{[82]}$ for plastics. Even though their performance was satisfactory, no commercial development was started. The $\mathrm{X}$-ray crystal structures of several isoxindigos and dibenzonaphthyrones were published ${ }^{[81 b, 83]}$ by Becker and coworkers.

The investigation of the chemistry of isoxindigos and similar dyes, triggered by the discovery of the novel synthesis of 55, was continued at Ciba for few years in late 1990s, in part by new colleagues. In particular, numerous novel dyes were prepared ${ }^{84]}$ via condensation of carbonyl derivatives with various $\mathrm{CH}_{2}$-active compounds. Noteworthy is the product $\mathbf{5 8}$ from condensation of isatin with the bis-benzofuranone 57 (Scheme 14).

This derivative, synthesized in 1999 by the colleague Dr. Thomas Ruch, is a deep black, insoluble solid (Fig. 4).

However, 58, although absorbing light throughout the visible spectrum, is virtually transparent for light with wavelengths $>720 \mathbf{n m}$, which means that $\mathbf{5 8}$ is not absorbing near infrared radiation (NIR, 780$2500 \mathrm{~nm}$ ). This results in the increase in temperature due to NIR absorption being strongly reduced compared to dyes and pigments that absorb strongly in the NIR region. Consequently, $\mathbf{5 8}$ was named 'cool

black', and has been evaluated as a pigings for cars. Indeed, the use of $\mathbf{5 8}$ signifi- architecture of the LCD matrix. The black color and, most importantly, the electrical non-conductivity of $\mathbf{5 8}$ makes it an ideal material for the BCS application.

The bis-oxodihydro-indolylene-benzodifuranone 58, described to the best of our knowledge for the first time in our patent, ${ }^{[84]}$ generates currently remarkable interest in the field of organic electronics and materials science. In 2013 the first report $^{[88]}$ on a semiconducting donor-acceptor copolymer for thin film transistors (TFT) appeared, consisting of thiophene and $\mathbf{5 8}$ as an electron acceptor unit. Since then, over 15 additional papers have been published, see refs. [89] and literature cited there. The alternating copolymer from electron-accepting $\mathbf{5 8}$ and electrondonating bithiophene units shows a low band gap of only $1.52 \mathrm{eV}$ and consequently strong and narrow absorption in the NIR $\left(\lambda_{\max }=811 \mathrm{~nm}\right)$. This contrasts strongly with the virtual transparency of pure $\mathbf{5 8}$ above $720 \mathrm{~nm}$ ! The authors ${ }^{[90]}$ suggest that this polymer may be useful for cancer photothermal therapy.

The chemistry described in this chapter is a nice example of serendipity in research. When the red impurity in the Irganox ${ }^{\circledR} \mathrm{HP}$ 136 reaction mixture was first spotted, nobody thought at this moment that pursuing this observation will years later result in a new black material for better LCD displays! ment for coloration of black parts in car interiors, e.g. car dashboards, and in coatcantly reduced the heating ${ }^{[85]}$ of the vehicle during sunny summer days. Unfortunately, some secondary properties of $\mathbf{5 8}$ were insufficient to allow its use in the extremely demanding applications present in the automotive industry.

On the other hand, $\mathbf{5 8}$ was recently successfully established under the trade name Irgaphor $^{\circledR}$ S100 Black CF as a novel material $^{[86]}$ for liquid crystal displays (LCD). The latest generation of LCDs uses a technology called color on array (COA) or color on TFT $(\mathrm{COT}, \mathrm{TFT}=$ thin film transistor), which allows the manufacturing of curved LCD displays. Important part of this novel LCD architecture is the black column spacer $(\mathrm{BCS})^{[87]}$ which separates the three sub-pixels (red/green/blue) of each color pixel, and simplifies the entire

\section{Environmentally Friendly Polymerization Inhibitors}

The majority of radically polymerizable monomers and formulations must be protected during manufacturing and storage from unwanted premature polymerization by admixture of small amounts of polymerization inhibitors which rapidly and efficiently scavenge initiating and/ or propagating radicals. A distinction between in-process and storage stabilizers is sometimes made. An ideal inhibitor will prevent polymerization during an adjustable period of time, which is known as an induction period. Once the inhibitor is consumed, polymerization will proceed at the rate determined by the actual conditions (e.g. monomer concentration, rate of initiation). Inhibitors which do not show

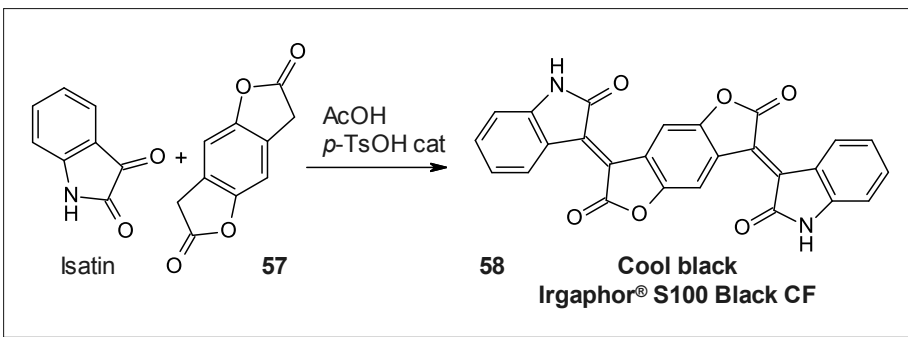

Scheme 14. Cool black or Irgaphor ${ }^{\circledR}$ S100 Black CF. 
a distinct induction period but rather slow down polymerization are sometimes called retarders. The topic has been reviewed ${ }^{[91]}$ several times. Common inhibitors include stable radicals such as galvinoxyl, nitroxide radicals, diphenylpicrylhydrazyl, substituted phenols, hydroquinones, quinones, nitrones, nitro- and nitroso compounds, $\mathrm{N}, \mathrm{N}$-diethylhydroxylamine or phenothiazine. The phenolic or hydroquinone inhibitors require ${ }^{[92]}$ traces of oxygen to be fully effective. In fact, phenols are rather poor scavengers of $\mathrm{C}$-centered radicals. The latter, however, react very rapidly with oxygen affording peroxyl radicals which are efficiently scavenged by phenols. For this reason, the oxygen content in large storage tanks containing acrylic or methacrylic acid and p-methoxyphenol (100 $200 \mathrm{ppm}$ ) as polymerization inhibitor is continuously monitored and maintained at a specific level. Oxygen itself is also very efficient polymerization inhibitor. ${ }^{[93]}$ An illustrative case of a runaway acrylic acid polymerization caused by insufficient inhibition due to lack of oxygen was described ${ }^{[94]}$ by Levy and Penrod.

A special family of polymerization storage inhibitors are the so-called in-can stabilizers. They are employed for stabilization of inks (flexo-, screen-, offset-, letterpress- and inkjet inks) and varnishes which are cured photochemically with UVlight. Such inks and varnishes are complex mixtures consisting of polyfunctional radically polymerizable monomers and oligomers (mostly acrylates), pigments, photoinitiators, dispersing agents and other additives. ${ }^{[95]}$ A premature polymerization at even a very small extent during their storage and transport in closed containers (cans) would lead to viscosity increase and gelation and render them unusable. Therefore, very efficient anaerobic polymerization inhibitors must be added. Phenolic inhibitors like 59 or 60 (Scheme 15) are not suitable for this purpose due to the oxygen-depleted atmosphere in the closed cans containing these inks. Phenothiazine $\mathbf{6 1}$ and 4-hydroxy-TEMPO 62 are powerful anaerobic inhibitors which are used to some extent. Unfortunately, they suffer from disadvantages like low solubility or discoloration (especially 61). Additionally, $\mathbf{6 2}$ is almost too efficient in scavenging of $\mathrm{C}$-centered radicals because in the desired photopolymerization $\mathbf{6 2}$ must be rapidly 'overrun' by a higher concentration of photochemically produced radicals to start the crosslinking reaction. For these reasons, nearly all commercial in-can stabilizers contain 300-1500 ppm of the aluminum salt of $\mathrm{N}$-nitrosophenylhydroxylamine $\mathbf{6 3}$ as main stabilizer. ${ }^{[96]}$ Unfortunately, even though the toxicological properties of $\mathbf{6 3}$ have not been officially evaluated until now, many companies classify it as potential carcinogen with an unpredictable future.

Consequently, an in-can stabilizer with better toxicological properties is highly desirable. Our discovery and development of a new, environmentally benign in-can stabilizer is described along the following lines.

I started my work on polymerization inhibitors in 1993 during a stay at the Ciba research center in Ardsley, USA. The focus at that time was on novel process (for distillation) stabilizers for acrylates, methacrylates and styrene. In a first approach, C-C dimers of diphenylacetonitrile 64, or of 9-cyanoxanthene $\mathbf{6 6}$, and derivatives were evaluated as inhibitors [97] for acrylic acid and its esters (Scheme 16). The actual inhibiting species are the C-centered, persistent radicals, e.g. 65, which are formed via thermal dissociation of their dimers. For instance, the bond dissociation enthalpy of $\mathbf{6 4}$ is only $26.2 \mathrm{kcal} /$ mol. ${ }^{[48 k]}$ The pink colored radical ${ }^{[73]} \mathbf{6 5}$ is, similarly to the blue radical $\mathbf{3 8}$, practically inert towards oxygen but it scavenges rapidly peroxyl-[47k] and especially $\mathrm{C}$-centered radicals which are propagating the polymerization. However, one should note that 64 can also promote ${ }^{[98]}$ oligomerization of monomers which are forming more stable propagating radicals (styrene or methacrylates). Additionally, 66 and its precursor 9-cyanoxanthene were identified by Dr. R. Pitteloud, working in the same group as me, as remarkably active experimental processing stabilizers ${ }^{[99]}$ for polymers. To conclude, even though $\mathbf{6 4}$ and $\mathbf{6 6}$ and their derivatives were good inhibitors, their commercialization was not pursued for various reasons such as too high cost or toxicological concerns.

From the numerous other evaluated substance classes finally emerged the, at that time not yet explored, quinone methides (QM) as most promising. Amongst the large number of compounds we have synthesized, the structures 67-70 were identified as the most active inhibitors. Their mode of action as radical scavengers is shown in Scheme 17. Thus, the radicals $\mathrm{X}^{\bullet}$, which are initiating or propagating the polymerization, add to the exocyclic double bond of the QMs to afford the relatively stable phenoxy radicals 71a which can be described also as their resonance hybrids 71b. These phenoxy radicals are unable to initiate novel polymeric chains, but can add and thus deactivate a second radical $X^{*}$ to afford the non-radical species $\mathbf{7 2}$.

The radical trapping by QMs, reported ${ }^{[100]}$ already 24 years ago, also explains the contribution of QMs to the stabilization of polymers ${ }^{[101]}$ with phenolic antioxidants from which they may be formed in situ.

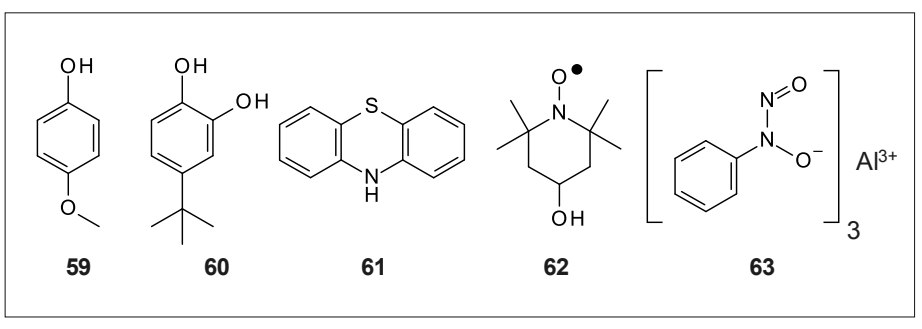

Scheme 15.

Examples of polymerization inhibitors.

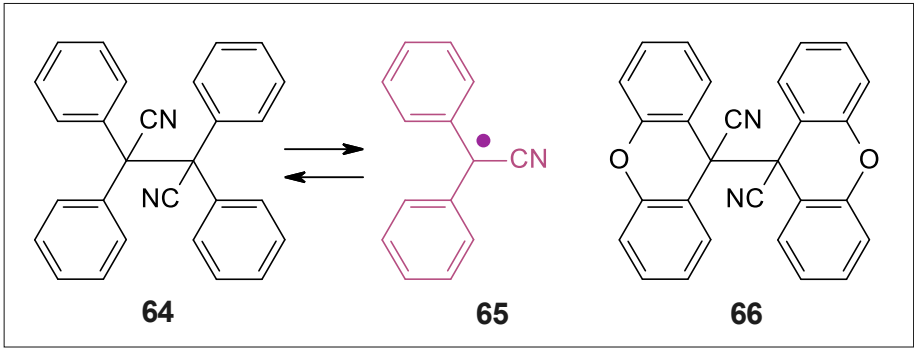

Scheme 16. Dimers of persistent C-radicals as polymerization inhibitors.
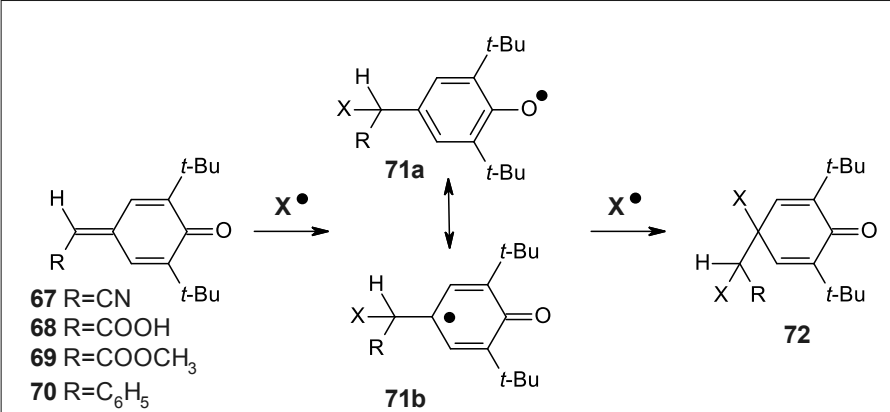

Scheme 17. Quinone methide as polymerization inhibitors. 
The inhibition mechanism of $\mathbf{7 0}$ according to Scheme 17 has been confirmed experimentally with styrene as a monomer by Motyakov and coworkers ${ }^{[102]}$ and later by Neilson and Morisson. ${ }^{103]}$ Recently, the radicophilic reactivity of QMs has been used for mild hydroalkylation of olefins, ${ }^{[104]}$ or for novel access to spiro[4.5] deca-6,9-dien-8-ones. ${ }^{[105]}$

The next task after identification of the outstanding inhibitor activity[106] of 67-70 was the development of their economically viable, upscalable synthesis. Several methods for making QMs are known, e.g. oxidation of the corresponding phenols with alkaline $\mathrm{K}_{3} \mathrm{Fe}(\mathrm{CN})_{6}$ (for more see ref. [107] and literature cited therein), unfortunately none of them appeared suitable for large-scale synthesis. Our improved procedure ${ }^{[106 a, 107]}$ for 67-69 is shown in Scheme 18. The key step is the 1,6-elimination of piperidine, $\mathrm{HCl}$ or methanol (in the case of $\mathbf{6 9}$ occurs during the esterification of the $\mathrm{COOH}$ group the concomitant substitution of the benzylic $\mathrm{Cl}$-atom with methanol) from the intermediates which are readily available from the very cheap 2,6-di-t-butylphenol (73). Interestingly, with 68 we have observed ${ }^{[108]}$ a new cyclodimerization affording the spirocyclohexadienone 74. Similar 1,6 nucleophilic additions/cyclizations of para-quinone methides leading to spirocyclohexadienones later became quite popular, see literature cited in ref. [105].

Based on practical and costs reasons, the compound $\mathbf{7 0}$ was finally selected for upscaling, even though 67-69 are slightly more efficient inhibitors. The key intermediate of the proprietary synthesis ${ }^{[109]}$ of 70, to which Dr. S. Evans from our group made the biggest contribution, are the Mannich bases. In situ treatment of the latter with acetic anhydride affords $\mathbf{7 0}$ and $N, N$-dialkyl acetamide (e.g. dimethyl acetamide) and acetic acid as the only side products.

The quinone methide $\mathbf{7 0}$ is a crystalline powder, m.p. $74-5^{\circ} \mathrm{C}$, well soluble in lipophilic monomers. It is currently commercialized as $\sim 15 \%$ solution in acrylate monomers under the trade names Irgastab ${ }^{\circledR}$ UV 22 and Irgastab ${ }^{\circledR}$ UV 25. Most importantly, due to the very favorable toxicological and migration properties of 70, both Irgastab ${ }^{\circledR}$ UV 22 and Irgastab ${ }^{\circledR}$ UV 25 have been approved by German and Swiss authorities for use in UV-printing inks for packaging coming into contact with food.

\section{Nitroxides and Alkoxyamines Controlled Radical Polymerization}

"I am inclined to think that the development of polymerization is, perhaps, the biggest thing chemistry has done, where

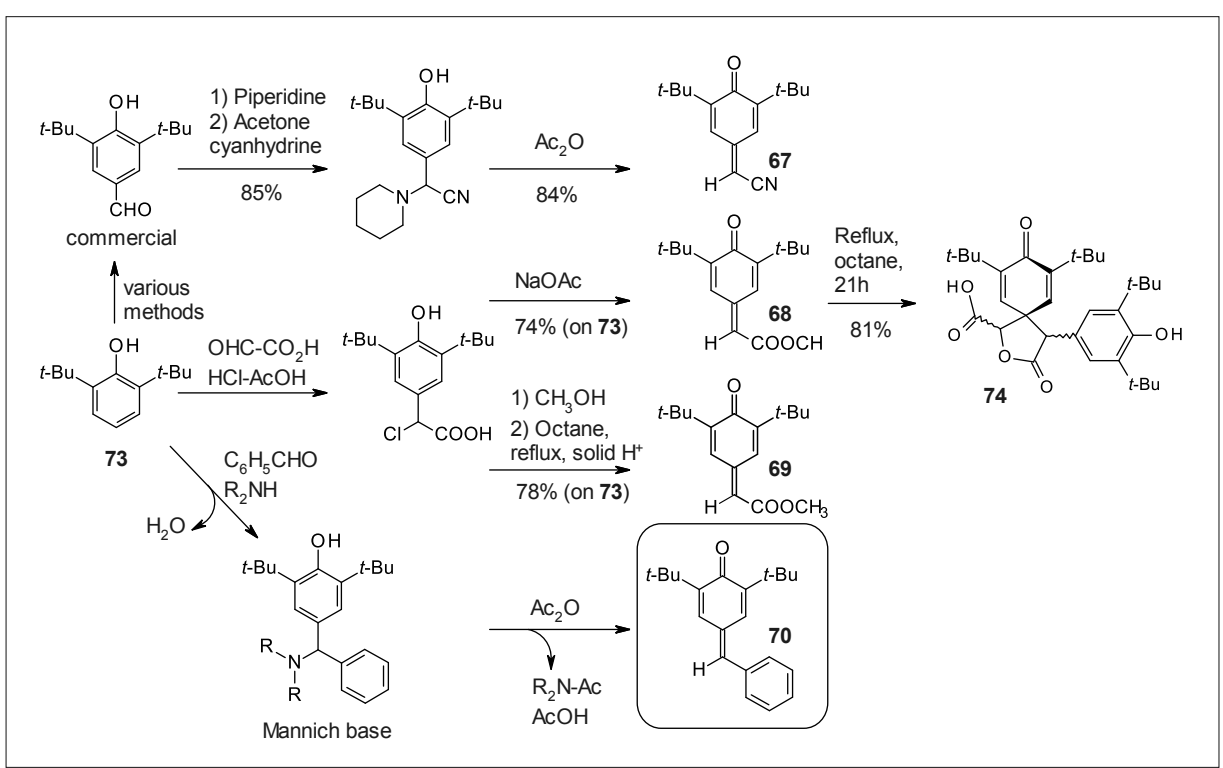

Scheme 18. Synthesis of quinone methides 67-70.

it has had the biggest effect on everyday life". (Lord Alexander Todd, President of the Royal Society of Chemistry, 1980). ${ }^{[110]}$

Synthetic polymers are prepared from low molecular weight monomers by a process called polymerization. Amongst the most important polymerization techniques is radical polymerization (RP) which belongs to the class of chain-growth polymerizations. In contrast to ionic or coordination polymerization, $\mathrm{RP}$ is tolerant to protic solvents and trace impurities like oxygen, $\mathrm{CO}_{2}$, or monomer stabilizers. Consequently, it can be conducted in polar solvents such as alcohols or, more importantly, water, with monomers which are not rigorously dried or purified. Furthermore, large numbers of inexpensive monomers suitable for this technology are available. From an industrial and economical point of view, RP is the technique of choice and polymers produced by RP represent roughly $40-45 \%$ of all industrial polymers. ${ }^{[111]}$ Prior to the mid 1980s, classical RP did not allow the synthesis of polymers with precisely designed molecular architectures, such as block, comb, or star copolymers, or polymers with defined terminal functional groups or narrow molecular weight distributions. Many of these polymeric architectures were only accessible by non-radical living polymerizations. As defined ${ }^{[12]}$ by IUPAC, a living polymerization is a "chain polymerization from which chain termination and irreversible chain transfer are absent." The first living polymerization technique, which was discovered in 1956 by Michael Szwarz, was living anionic polymerization. ${ }^{[113]}$ Over the years, other controlled and living polymerizations such as group transfer polymerization, living carbocationic polymerization, living ring opening metathesis polymerization, or living transition metal catalyzed alkene polymerization were developed. For a recent overview of the state of the art of controlled and living polymerizations see the monograph ${ }^{[14]}$ of Müller and Matyjaszewski and the 2017 review ${ }^{[15]}$ by R.B. Grubbs and R.H. Grubbs.

Unfortunately, non-radical living polymerization processes are incompatible with many functional groups, and require highly pure monomers and solvents as well as the exclusion of oxygen and water. In contrast, the controlled and living $\mathrm{RP}$ combines the robustness of a classical $\mathrm{RP}$ with the power of living polymerization and thus allows the preparation of complex polymeric structures. The term controlled polymerization was coined ${ }^{[116]}$ by Matyjaszewski and Müller in 1997 and is defined[114] "as a synthetic method to prepare polymers which are well defined with respect to topology (e.g. linear, starshaped, comb-shaped, dendritic, and cyclic), terminal functionality, composition, and arrangement of co-monomers (e.g. statistical, periodic, block, graft, and gradient), and which have molecular weights predetermined by the ratio of concentrations of reacted monomer to introduced initiator, as well as a designed (not necessarily narrow) molecular weight distribution $\left(M W D=M_{w} / M_{n}\right)$. Thus, according to the definition given above, a living polymerization is not always controlled and a controlled polymerization is not always strictly living. In the ideal case, a living polymerization is also controlled; however, in some systems such as in a radical polymerization, termination can never be entirely avoided although its contribution can be sometimes significantly reduced."

Several controlled and living radical polymerization techniques are available today, namely, a) atom-transfer radical polymerization $^{[117]}$ (ATRP), b) reversible- 
chain-transfer catalyzed polymerization ${ }^{118]}$ (RTCP), c) degenerate-transfer radical polymerization ${ }^{[119]}$ (DTRP) of which the most prominent variant is the reversible-addition-fragmentation chaintransfer polymerization[120] (RAFT) and, d) stable-radical-mediated polymerization (SRMP; a review ${ }^{[121]}$ of which was written by myself in 2013). As the published literature on these methods is overwhelmingly abundant, only few recent reviews are cited. All these polymerizations are based on the reversible deactivation of growing polymeric chains. Consequently, a 2010 IUPAC recommendation ${ }^{[112]}$ proposed the term 'controlled reversible-deactivation radical polymerization (CRDRP)' for polymerizations previously referred to as 'controlled' radical (CRP) or 'living' radical (LRP) polymerization. Nevertheless, due to their widespread acceptance, the terms CRP and LRP are still being used.

Below are described our contributions to commercialization of nitroxide mediated radical polymerization (NMP) which is the most important method of stable-radical-mediated polymerizations (SRMP). NMP was discovered in 1984 at the Commonwealth Scientific and Industrial Research Organization (CSIRO) in Australia. The history of this discovery is recounted in several articles. ${ }^{[122]}$ This pioneering work, first published as a patent ${ }^{[123]}$ only, attracted broad attention in 1993 when Georges and coworkers reported ${ }^{[124]}$ the synthesis of polystyrene with narrow MWD via NMP of styrene mediated by 2,2,6,6-tetramethylpiperidine-N-oxyl (TEMPO). Abundant literature on NMP exists: a very good overview of the current state is provided by the review ${ }^{[125]}$ of Nicolas, Guillaneuf and coworkers and the monograph ${ }^{[126]}$ of Gigmes. Key species in NMP are the nitroxide radicals; for space reasons, only some excellent reviews ${ }^{[126,127]}$ on their synthesis and properties are given. NMP is an attractive, simple and straightforward technique, because typically only monomer and an appropriate alkoxyamine initiator are needed to conduct the polymerization.

A simplified general mechanism of NMP is depicted in Scheme 19 with the example of the TEMPO-based alkoxyamine 75. A solution of $\mathbf{7 5}$ in monomer is heated to the appropriate temperature at which the weak $(\mathrm{BDE}=30 \mathrm{kcal} / \mathrm{mol})^{[128]} \mathrm{NO}-\mathrm{C}$ bond of $\mathbf{7 5}$ undergoes reversible homolysis (rate constant $k_{\mathrm{d}}$ ) to yield a persistent TEMPO nitroxide 76 and a transient radical 77 . The highly reactive 77 can either recombine $\left(k_{\mathrm{c}}\right)$ with 76, terminate with itself or add to monomer $\mathrm{CH}_{2}=\mathrm{CH}-\mathrm{Y}$ to afford a growing polymeric chain radical. The termination reactions of the $\mathrm{C}$-centered radicals are strongly diminished in comparison to classical RP due to the persistent radical effect.[129]

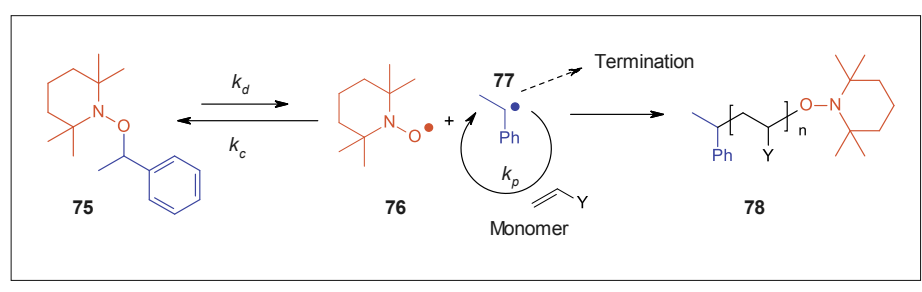

Scheme 19. NMP with the TEMPO alkoxyamine initiator 75 .

Result of many iterations of this process is the polymer $\mathbf{7 8}$ consisting of long polymeric macro-alkoxyamine chains. The MWD of this polymer is narrow because all chains essentially grow in parallel, and its number average degree of polymerization DP after sufficiently long time is giv$\mathrm{en}^{[130]}$ by the ratio [converted monomer]/ $[75]_{0}$. In other words, the polymerization is controlled. Moreover, as the chains of the polymer bear reactivable nitroxide end groups, the polymer is living, and polymerization and chain growth will resume upon addition of fresh monomer. Similarly, addition of a different monomer will result in a block copolymer.

It must be noted that Scheme 19 shows an idealized picture of NMP. In the real NMP process various side reactions can occur, ${ }^{[131]}$ e.g. decomposition of the nitroxide or alkoxyamine or autoinitiation of the monomer. Nevertheless, the understanding of all kinetic subtleties of NMP is currently already at a very high level.[132]

Our work on NMP started in the mid 1990s. The decision to focus on NMP was a logical one because Ciba was at that time one of the major producers of derivatives of 2,2,6,6-tetramethylpiperidine (e.g. 3, Scheme 2 and 62, Scheme 15). Additionally, compared to copper-mediated ATRP, NMP is considered 'cleaner', even though methods requiring only small amounts of $\mathrm{Cu}$ were developed in the meantime. ${ }^{[133]}$ Color or odor issues were of concern with sulfur-containing RAFT.

A serious drawback of TEMPOalkoxyamine initiators is that efficient NMP is possible only with styrene and its derivatives, but not with acrylates, which are very important for practical applications. In fact, the rate constants $k_{\mathrm{d}}$ and $k_{\mathrm{c}}$ of the alkoxyamine initiator, and especially of the related growing macro-alkoxyamine, must be in a defined range to achieve living and controlled polymerization of a given monomer at specific temperature to a targeted degree of polymerization. ${ }^{[132]}$

For our development of more versatile alkoxyamines and nitroxides than $\mathbf{7 5}$ or $\mathbf{7 6}$, we combined iterative empirical approach coupled quantitative measurements ${ }^{[134]}$ of the $k_{\mathrm{d}}$ and $k_{\mathrm{c}}$ rate constants of the prepared molecules. These were performed in the group of Prof. H. Fischer at the University of Zürich. The following examples illustrate only the most interesting compounds and approaches evaluated during this work.
Amongst the first concepts we studied were alkoxyamines obtained via addition of radicals generated from conventional radical initiators such as azo-bis-isobutyronitrile (AIBN) or 1,1'-azobis(cyclohe xanecarbonitrile) (ACCN) to nitrones and nitroso compounds. Rapid and controlled polymerization of styrene was indeed achieved ${ }^{[135]}$ with the alkoxyamines $\mathbf{8 1}$ and 84 (Scheme 20), but not with $n$-butyl acrylate $(n-\mathrm{BuA})$. Therefore, we have not followed this concept further. Nevertheless, this approach attracted later some academic interest ${ }^{[136]}$ because the starting materials are inexpensive and, in principle, the nitroxide or alkoxyamine could be formed in situ (e.g. $\mathbf{7 9} \rightarrow \mathbf{8 0} \rightarrow \mathbf{8 1}$ or $\mathbf{8 2} \rightarrow \mathbf{8 3} \rightarrow \mathbf{8 4})$ in the polymerizing mixture. However, these systems are much more complex than those using a pure alkoxyamine initiator, and the underlying mechanisms must be well understood before such systems can be optimized and applied industrially. The state of the art of this so-called in situ NMP as of 2008 was reviewed ${ }^{[137]}$ by Detrembleur and coworkers. An interesting variant of in situ NMP which uses alkoxyamines formed by addition of polymeric radicals to nitrones or nitroso compounds is the so-called enhanced spin capturing polymerization ${ }^{[138]}$ (ESCP).

In the next approach we used the old (discovered in 1906) Bargellini reaction $^{[139]}$ for the synthesis of novel morpholinones $(\mathrm{X}=\mathrm{O})$ or piperazinones $\left(X=N_{5}\right) 85$ (Scheme 21). Oxidation provided the nitroxides $\mathbf{8 6}$ which were coupled with photochemically generated $\alpha$-methylbenzyl radicals to afford the alkoxyamines 87. A clear trend was observed in the evaluation of the around 100 synthesized alkoxyamines ${ }^{[140]}$ in polymerization of styrene and $n$-BuA. The speed of polymerization increased with increasing steric hindrance of the NO group in the nitroxides (e.g. 88 $\rightarrow \mathbf{9 0}$ or $\mathbf{9 2} \rightarrow \mathbf{9 4}$ ) and related alkoxyamines $(\mathbf{8 9} \rightarrow \mathbf{9 1}$ or $\mathbf{9 3} \rightarrow \mathbf{9 5})$. Most importantly, efficient controlled and living polymerization of $n$-BuA was obtained with the sterically hindered alkoxyamine 91 and especially with 95.

We then quantitatively demonstrated[134c] the effect of steric hindrance on the rate constants $k_{\mathrm{d}}$ and $k_{\mathrm{c}}$ of six piperazinone alkoxyamines 87 with systematically varied substituents $\mathrm{R}_{1}-\mathrm{R}_{4}$. As expected, $k_{\mathrm{d}}$ increased and $k_{c}$ decreased with the steric hindrance. As a consequence, the equilib- 


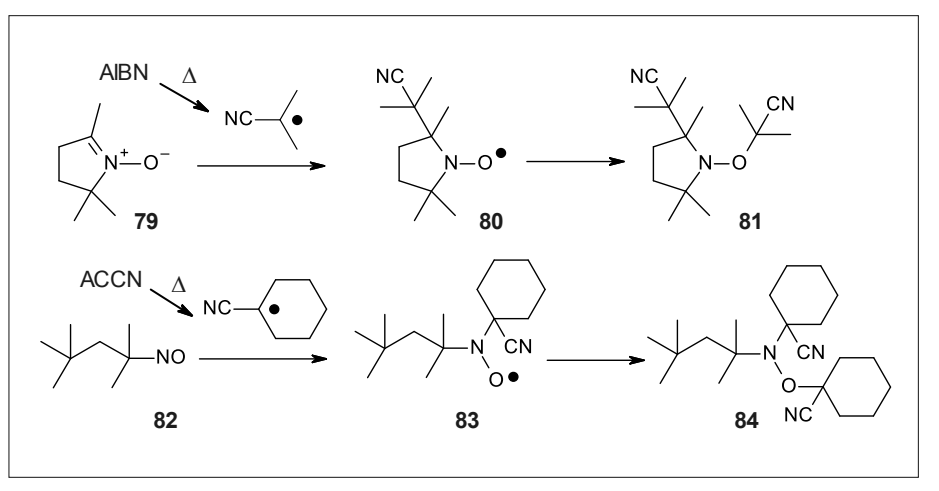

Scheme 20. Nitroxides and alkoxyamines from nitrones and nitroso compounds. rium constants $K=k_{\mathrm{d}} / k_{\mathrm{c}}$ for $\mathbf{9 3}\left(\mathrm{K}_{393}=4.2\right.$ $\left.\times 10^{-13} \mathrm{M}\right)$ and $95\left(\mathrm{~K}_{393}{ }^{\mathrm{c}}=1.4 \times 10^{-10} \mathrm{M}\right)$ differ by 2 orders of magnitude. It should be noted that the steric parameters of the nitroxide $\left(\mathrm{R}_{1} \mathrm{R}_{2} \mathrm{NO} * ; \mathrm{R}_{1} \mathrm{R}_{2}\right.$ have a different meaning from that used in Scheme 21) and the released radical $\mathrm{R}^{\bullet}$ influence the $k_{\mathrm{d}}$ and $k_{\mathrm{c}}$ of the alkoxyamine $\left(\mathrm{R}_{1} \mathrm{R}_{2} \mathrm{NOR}\right)$ in a dominant way, however recent research ${ }^{[141]}$ showed that other factors $(e . g$. polar effects or hydrogen bonding) are also important.

Thus, with nitroxide 94 and alkoxyamine 95 we have identified highly efficient mediator and unimolecular initiator for NMP of styrenes and acrylates. This important development was lodged in our patent application ${ }^{[140]}$ filed on $16^{\text {th }}$ were already working on alternative chemistry which was more suitable for technical, large-scale production (vide infra). Therefore, the morpholinone and piperahigh priority. The academic community became aware of the outstanding properties of 94 and 95 probably only 10 years later after the joint paper ${ }^{[142]}$ with Prof. A. Studer and coworkers had been published in 2009, and which clearly stated that $\mathbf{9 4}$ and derivatives are "probably the most efficient cyclic 6-membered nitroxides known to date for mediating NMP". Since then, Studer and coworkers used 94 or 95 in several interesting applications, e.g. for controlled polymerization ${ }^{[143]}$ of methyl and phenyl vinylketone, polymerization ${ }^{[144]}$ of styrene and $n$-BuA in microflow tubular reactor, synthesis of alternating copolymers $^{[145]}$ of hexafluoroisopropyl acrylate with 7-octenyl vinyl ether or preparation ${ }^{[146]}$ of functional alternating polymer brushes. In 2014, the Studer's group reported ${ }^{[147]}$ polymerization of $n$-BuA at 60 ${ }^{\circ} \mathrm{C}$ and of styrene at $50{ }^{\circ} \mathrm{C}$ using even more sterically hindered piperazinone nitroxides and alkoxyamines than 94 and 95 (optimal polymerization temperature ${ }^{[142]}$ of $n$-BuA with 95 is $125-130{ }^{\circ} \mathrm{C}$ ).

It was natural to expect that steric hindrance would influence the NMP activity of analogues of TEMPO 76 (Scheme $19)$ in the same positive way as observed with 94 and 95 . The precursor of TEMPO, October 1998. At that time, however, we zinone chemistry was not followed with 2,2,6,6-tetramethylpiperidin-4-one $\quad \mathbf{9 6}$, Scheme 22) is a bulk chemical which is produced from acetone and $\mathrm{NH}_{3}$ by several companies as an intermediate for hindered amine light stabilizers (HALS), e.g. 3 (Scheme 2). Ciba was one of them, and there was extensive in-house know-how of this chemistry available. The logical step was therefore to try the synthesis of the yet unknown tetraethyl analogue 99. However, it became rapidly clear that development of an economically viable synthesis for the simple looking 99 would be difficult. Several multistep syntheses ${ }^{[148]}$ of 99 were reported later, first in 2004 by Studer and coworkers ${ }^{[148 d]}$ who also showed that the related nitroxides 100 and $\mathbf{1 0 3}$ and the corresponding alkoxyamines $\mathbf{1 0 1}$ and $\mathbf{1 0 4}$ indeed are highly efficient for NMP of styrene and acrylates.

We therefore switched our attention to $\mathbf{1 0 5}$, the 3,5-dimethyl derivative of $\mathbf{9 9}$. Compounds of this type, obtainable via reaction of $\mathrm{NH}_{3}$ with higher ketones than acetone, were described in the 1976 patent $^{[149]}$ of Ciba-Geigy as light stabilizers. Unfortunately, trials with diethyl ketone and $\mathrm{NH}_{3}$ afforded only traces of $\mathbf{1 0 5}$. On the other hand, the synthesis of 2,6-diethyl-2,3,6trimethylpiperidin-4-one (106) from ethyl methyl ketone worked without problem. The cited patent reports also the nitroxide 107. To our delight, the alkoxyamine 108 turned out to be highly efficient for NMP of acrylates and styrenes. In the context of this work, I wanted to know if the activity could further be increased, and polymerization temperature decreased, by increasing the steric congestion around be $\mathrm{N}-\mathrm{O}{ }^{\bullet}$ function further. To this end, we prepared from 1-hydroxy-2,6-di-t-butyl piperidine via repeated oxidation to nitrone and addition of Grignard reagent the nitroxides $\mathbf{1 0 9}$ and $\mathbf{1 1 0}$ and then the alkoxyamine 111 (unpublished results). Interestingly, the colorless 111 decomposed rapidly already at room temperature into the red nitroxide $\mathbf{1 0 9}$ (and other products), probably due to too high $k_{d}$ and/ or too low $k$. This was an indication that increasing the bulkiness of the nitroxide beyond a certain level would be detrimental. In 2006, Studer and coworkers addressed this question of "how much is too much" (of steric demand) quantitatively, and showed that the nitroxide $\mathbf{1 1 2}$ is already too bulky, making the trapping reaction of the nitroxide with the macroradical too slow. Therefore, the alkoxyamine $\mathbf{1 1 3}$ behaves like a classical radical initiator and $\mathbf{1 1 2}$ as spectator without any NMP-mediating capacity.

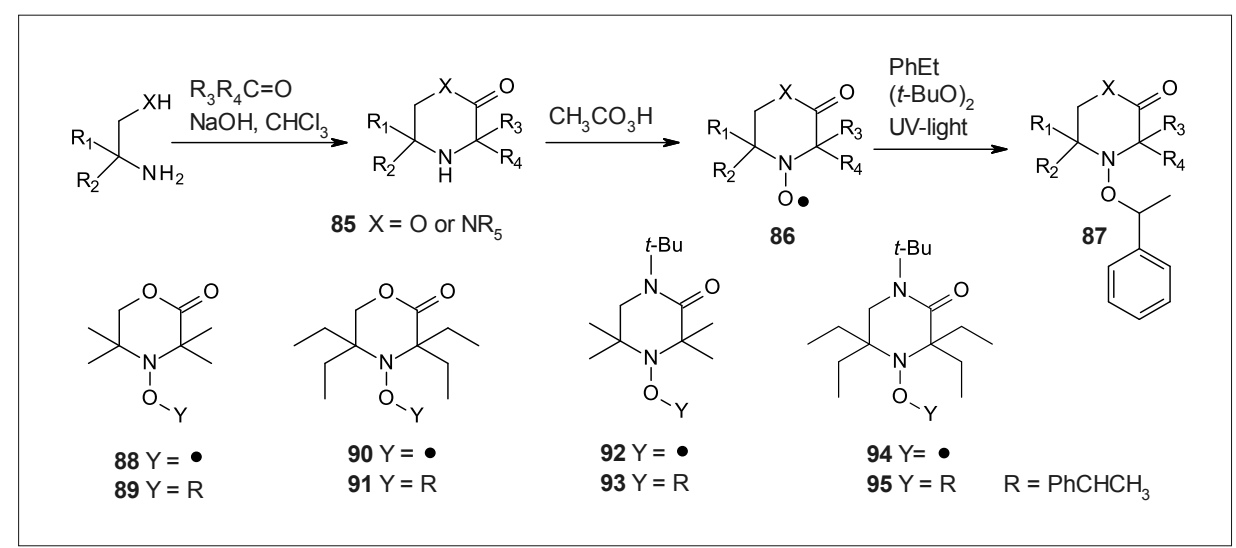

Scheme 21. Morpholinone and piperazinone nitroxides and alkoxyamines via the Bargellini reaction.

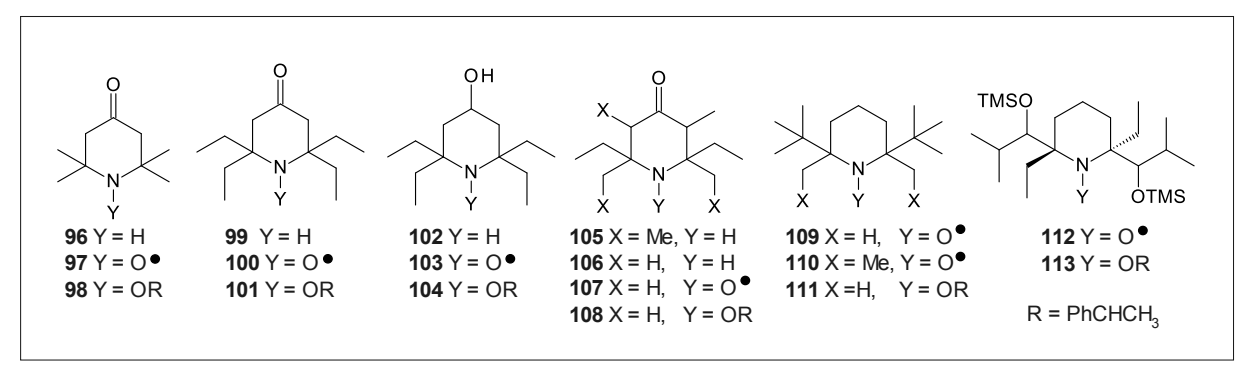

Scheme 22. Piperidine nitroxides and alkoxyamines. 
Consequently, uncontrolled NMP was obtained with the alkoxyamine $\mathbf{1 1 3}$.

Thus, we were convinced to have identified in $\mathbf{1 0 7}$ and 108 optimally active and economically feasible nitroxide and alkoxyamine for NMP. Therefore, the upscaling of 108, for which the patent ${ }^{[150]}$ application was filed on March $9^{\text {th }} 1998$, was initiated. The reaction sequence to $\mathbf{1 0 8}$ is shown in Scheme 23. Reaction of ethyl methyl ketone with $\mathrm{NH}_{3}$ under catalysis with weak acids as described in our publication $^{[151]}$ affords the piperidone $\mathbf{1 0 6}$ (the not isolated 2,4,6-triethyl-2,6-dimethyl-1,5-dihydropyrimidine intermediate ${ }^{[149]}$ is not shown). The product contains three asymmetric carbon atoms, consequently four diastereoisomers are expected. Indeed, four $\mathrm{CO}$ resonances are visible in the ${ }^{13} \mathrm{C}-\mathrm{NMR}$ spectrum ${ }^{[151]}$ of $\mathbf{1 0 6}$. Given its narrow boiling range and appearance as a single spot on thin layer chromatogram, the separation of the isomers by distillation or chromatography was not attempted. Accordingly, the structural formulae in Scheme 23 represent all possible diastereoisomers. Oxidation of $\mathbf{1 0 6}$ into the nitroxide $\mathbf{1 0 7}$ with the commonly used $\mathrm{H}_{2} \mathrm{O}_{2} / \mathrm{Na}_{2} \mathrm{WO}_{4}$ (e.g. for $\mathbf{9 6} \rightarrow \mathbf{9 7}$ ) system was too slow. Thus, we developed a better, proprietary method ${ }^{[152]}$ using $40 \%$ peracetic acid in combination with weak inorganic base. The transformation of $\mathbf{1 0 7}$ into $\mathbf{1 0 8}$ deserves a special note. The different methods for synthesis of alkoxyamines were reviewed by Blinco (p. 114 of ref. [126]), Marque,[153] Brémont,, ${ }^{[154]}$ and coworkers, and myself.[155] Most of them rely on coupling of C-centered radicals with nitroxides ${ }^{[141 \mathrm{~b}]}$ and work nicely in the laboratory, for example the $\mathrm{Cu}$ promoted coupling[156] of activated alkyl halides, e.g. $\mathrm{PhCHBrCH}_{3}$, with nitroxides. We have used this synthesis to produce $^{[151]}$ small quantities of $\mathbf{1 0 8}$. However, the $\mathrm{Cu}$-salts, amine ligand and alkyl bromide make this method unsuitable for large scale. Therefore, we have designed a new, proprietary process ${ }^{[157]}$ in which the phenethyl radicals $\mathrm{PhCH}^{\circ} \mathrm{CH}_{3}$ are generated from ethyl benzene and $t$-butyl hydroperoxide under catalysis with only very small amounts of $\mathrm{Cu}^{+}$or $\mathrm{Cu}^{2+}$ salts. These improvements resulted in a robust process delivering pure $\mathbf{1 0 8}$ as a colorless oil. The $>\mathrm{C}=\mathrm{O}$ function of $\mathbf{1 0 8}$ allows further simple functionalization. One example is the formation of the oxime $\mathbf{1 1 4}$ and its Beckmann rearrangement to the diazepanone alkoxyamine 115. For comparison, we have transformed also the alkoxyamine 98 into 116. With both $\mathbf{1 1 5}$ and 116, the ring expansion caused more efficient polymerization compared to the 6-membered ring precursors 108 and 98, respectively. ${ }^{[151]}$ Studer and coworkers ${ }^{[158]}$ prepared later similarly from 101 the diazepanone 117 and confirmed the higher activity of $\mathbf{1 1 7}$ with respect to $\mathbf{1 0 1}$. The beneficial effect of ring enlargement was demonstrated by the same group already ${ }^{[148 d]}$ on the alkoxyamines derived from 2,2,7,7-tetraethylazepan-4-one which was obtained from 99 with TMS-diazomethane. The alkoxyamine $\mathbf{1 0 8}$ is not soluble in water. Of course, hydrophilic derivatives can also be made from 107. One example is the watersoluble 118 which we have intercalated by cation exchange into a montmorillonite-type layered silicate. ${ }^{[159]}$ The ensuing NMP in the presence of $n$-BuA caused an almost complete exfoliation of the silicate layers. The poly $(n-\mathrm{BuA})$ modified silicate nanoparticles obtained by this process were used to make nanocomposites with novel properties, e.g. polyethylene films with reduced $\mathrm{O}_{2}$ permeability.

There are in the meantime so many nitroxides and alkoxyamines known[126] that it is not possible to review them all here.

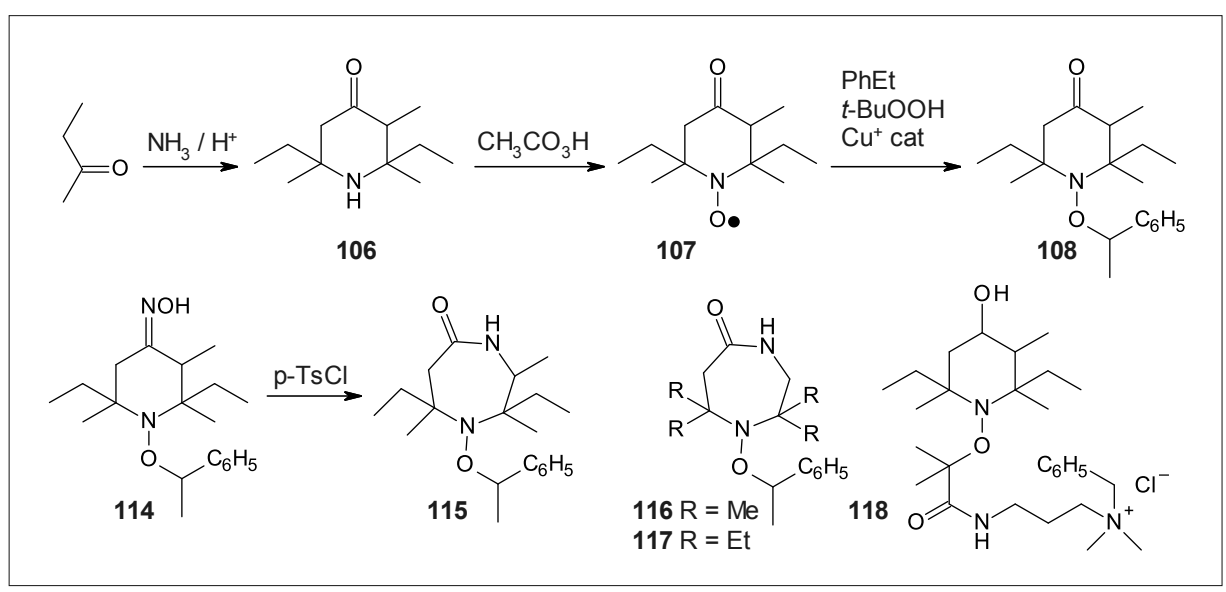

Scheme 23. Synthesis of the diethyl-trimethyl-piperidone nitroxide 107 and alkoxyamine 108, ring enlargement of piperidone alkoxyamines and hydrophilic alkoxyamine 118.

However, it seems that only our $\mathbf{1 0 7}$ and $\mathbf{1 0 8}$ were developed to commercialization, as well as by Arkema the so-called SG-1 radical 119 (Scheme 24), originally discovered by Tordo and coworkers, ${ }^{[160]}$ and its related alkoxyamine 120 (BlocBuilder $\left.{ }^{\circledR}\right) .{ }^{[161]}$

A review ${ }^{[162]}$ of the industrial obstacles and achievements of controlled reversible-deactivation radical polymerization (CRDRP) was written by Destarac. CRDRP opens completely new possibilities for the design and synthesis of novel materials. In 2000, the potential market for CRDRP products was, probably too optimistically, anticipated to exceed 20 billion US\$/year. It is now clear that CRDRP will not replace classical RP for production of large volume commodity polymers. However, its potential for high-value polymeric specialties remains intact. For instance, Arkema employs 120 for synthesis of acrylic block copolymers (Nanostrength $^{\circledR}$ ) used as tougheners for epoxy polymers.[163] However, the first industrial NMP employing $\mathbf{1 0 8}$ was realized $^{[164]}$ by Ciba in 2003. Using NMP, Ciba, and later BASF, developed and novative block copolymer pigment dispersants ${ }^{[166]}$ which offer advantages in rheology of pigment concentrates, their stability and coloristic properties. The A-B block copolymer pigment dispersant consists of an A-block with stabilizing groups, which compatibilize the dispersant within the medium and prevent pigment agglomeration and coagulation, and a B-block bearing suitable anchoring groups (e.g. dialkylamino) which adsorb to the surface of a pigment particle (Fig. 5). The chemistry and physics of polymeric pigment dispersants have been reviewed ${ }^{[167]}$ by Auschra and Pirrung.

An example of such an amphiphilic block copolymer $\mathbf{1 2 1}$ made with the alkoxyamine $\mathbf{1 0 8}$ is shown in Scheme 25. commercialized a whole range ${ }^{[165]}$ of in- 


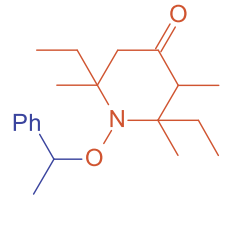

108

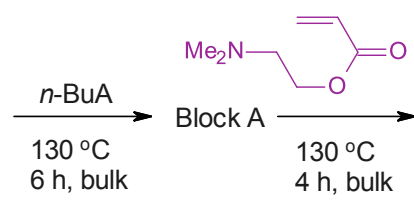

, bulk

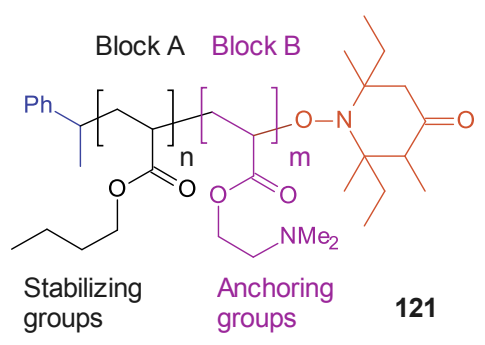

groups

groups

Scheme 25. Amphiphilic block copolymer 121 made by NMP for use as pigment dispersant.

The work leading to the commercialization of NMP was awarded in 2011 the prestigious Sandmeyer Award of the Swiss Chemical Society (C. Auschra, R. Knischka, A. Kramer, A. Mühlebach, P. Nesvadba, F. Pirrung, M. Roth).

Our last contribution to NMP deals with polymerization at high temperatures. Typically, NMP with alkoxyamines like $\mathbf{1 0 8}$ is performed at $110-130{ }^{\circ} \mathrm{C}$ to achieve 70 $80 \%$ monomer conversion within, say, $5 \mathrm{~h}$. Several groups, ${ }^{[161 b, 168]}$ including ours, ${ }^{[169]}$ demonstrated that the polymerization temperature can be below $100{ }^{\circ} \mathrm{C}$, which would for example allow fast NMP in water at normal pressure. We have then tried the opposite, i.e. to increase the polymerization temperature, hoping that the reaction time could be significantly shortened. A prerequisite for this, beside the fulfillment of the kinetic requirements, ${ }^{[132,170]}$ is the thermal stability of the nitroxide. Most nitroxides begin to decompose above $\sim 140{ }^{\circ} \mathrm{C}$, their stability has been reviewed[171] by Braslau and Nilsen. The 1,1,3,3-tetraphenylisoindoline-N-oxyl (122, Scheme 26) prepared by us ${ }^{[157 b]}$ in 2000 , is a rare exception. This high melting $\left(250-253^{\circ} \mathrm{C}\right)$ nitroxide is remarkably thermally stable, remaining unchanged after being heated for $7 \mathrm{~h}$ at $200{ }^{\circ} \mathrm{C}$ under air. In 2015, we had observed ${ }^{[172]}$ that the related alkoxyamines $\mathbf{1 2 3}$, and the more soluble 124, allowed an unprecedented controlled and living polymerization of styrene at temperatures up to $200{ }^{\circ} \mathrm{C}$ with MWD's of 1.2 for styrene and 1.5 for $n$-BuA. High monomer conversions were reached in a few minutes with a linear increase in polymer chain-length with conversion. Controlled polymerization of methacrylate monomers and acrylic acid was also successful with the addition of styrene. Thus, these new, proprietary ${ }^{[173]}$ alkoxyamines open the possibility to rapidly produce block copolymers in continuous reactors ${ }^{[174]}$ under high temperature conditions.

\section{Safe Radical Initiators}

During our work on NMP, hundreds of different alkoxyamines $R_{1} R_{2}$ NOR were prepared, and the roles of the nitroxide $\mathrm{R}_{1} \mathrm{R}_{2} \mathrm{NO}^{\bullet}$ and of the radical $\mathrm{R}^{\bullet}$ have been systematically studied. Within this work, the $\mathrm{N}$-acyloxyamines $\mathrm{R}_{1} \mathrm{R}_{2} \mathrm{NOCOR}_{3}$ were also evaluated. Such compounds were patented by Ciba in late 1980s as light stabilizers ${ }^{[175]}$ for coatings, but were not commercialized. To our surprise, the $\mathrm{N}$-acyloxyamines caused, above $100{ }^{\circ} \mathrm{C}$, polymerization of a variety of monomers (styrene, acrylates, methacrylates). However, the polymers had high MWD (2-20) and were not living. A few examples, 125-8, from our broad patent application ${ }^{[176]}$ are shown in Scheme 27. They are readily prepared via reduction of nitroxides, followed by acylation of the intermediate hydroxylamines.

Obviously, the mechanism by which the N-acyloxyamines trigger the polymerization is different to that observed in NMP with $N$-alkoxyamines. Thermolysis of most alkoxyamines induces the homolysis ${ }^{[177]}$ of the NO-C bond affording persistent nitroxides and transient alkyl radicals (Scheme 19). Accurate quantum chemical calculations ${ }^{[131 b]}$ showed that the alternative dissociation of the $\mathrm{N}-\mathrm{OC}$ bond of TEMPO-based alkoxyamines is energetically disfavored by at least $12 \mathrm{kcal} /$ mol. Nevertheless, exceptions to this rule exist, and N-OC cleavage is observed[178] with alkoxyamines which form stabilized aryl aminyl radicals. Our original explanation of the different reactivity of $N$-acyloxyamines from late 1990 s is based on my DFT-calculations (RO-B3P86/6311G(2d,2p)//B3LYP/6-31G(d), 298K, 1 atm) which suggested their N-OC homolysis. This is exemplified in Scheme 28 on $\mathrm{N}$-acetyloxyamine 129 which affords two reactive radicals, tetramethyl-piperidinyl 130 and acetyloxy 131 which very rapidly decarboxylates ${ }^{[179]}$ into $\mathrm{CO}_{2}$ and methyl radical (path A). The BDE's values shown in Scheme 28 were calculated ${ }^{[180]}$ in 2013 by Gigmes and coworkers with the chemically accurate G3(MP2)-RAD method, and are $c a .5 \mathrm{kcal} / \mathrm{mol}$ higher than my DFT numbers. Little is known about reactivity of transient aminyls such as 130. Coote and coworkers $^{[8 \mathrm{~b}]}$ provided high level computation arguments for their involvement in revised mechanism of hindered amine light stabilizers (HALS). The $\beta$-fragmentation similar to $\mathbf{1 3 0} \rightarrow \mathbf{1 3 3}$ was observed ${ }^{[181]}$ in 2015 by mass spectrometry on a 4-carboxy analogue of 130. My own G3(MP2) calculation indicates that this fragmentation is only slightly endothermic $\left(\Delta \mathrm{H}_{298 \mathrm{~K}}=+13.9\right.$ $\mathrm{kcal} / \mathrm{mol}$ ), therefore, the positive entropy change should make it favorable with increasing temperature. Consequently, this $\beta$-fragmentation may be an important source of alkyl radicals at high temperatures. Thus, path A would generate several reactive radicals able to initiate polymerization (i.e. 131, ${ }^{\circ} \mathrm{CH}_{3}$, perhaps also 130 ).

However, we later observed that almost stoichiometric amounts of acetic acid were formed when 129 and analogues were used as radical generators for controlled degra-

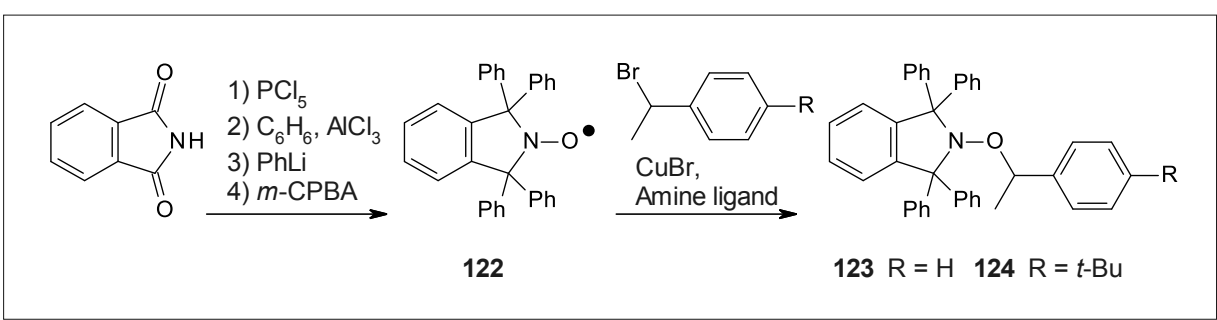

Scheme 26. Thermally stable nitroxide 122 and alkoxyamines 123, 124 for high temperature NMP up to $200^{\circ} \mathrm{C}$.

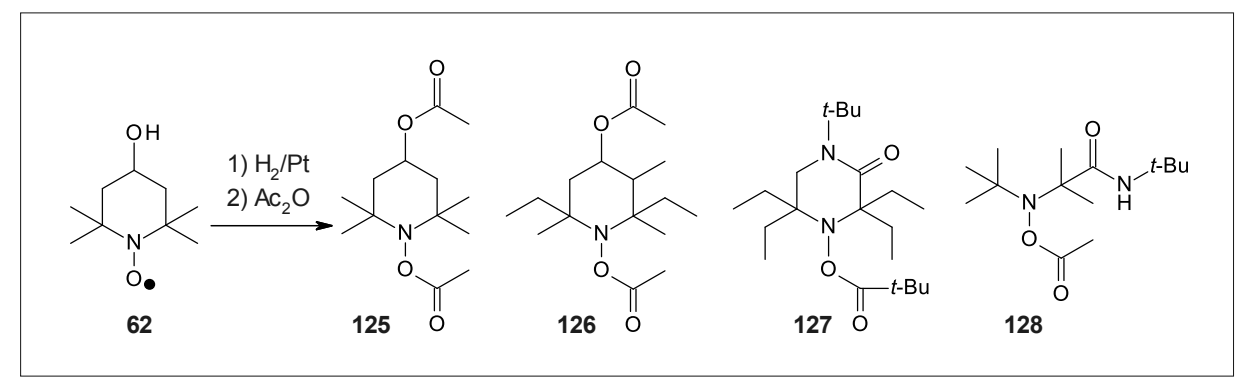

Scheme 27. N-Acyloxy-hydroxylamines as thermal radical initiators. 


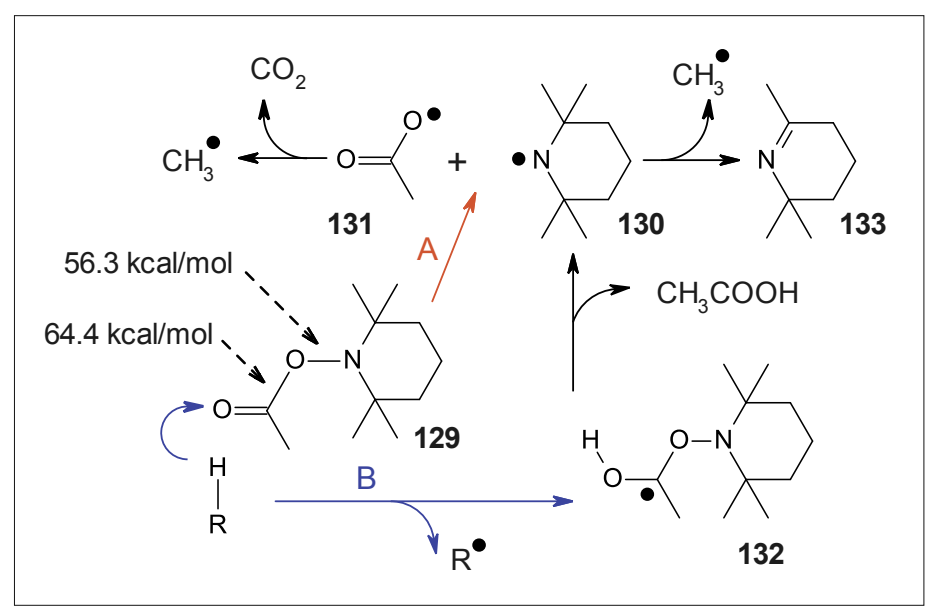

Scheme 28. $\mathrm{N}$-Acetyloxyamine 129 as thermal radical initiator. dation of polypropylene (vide infra). The extremely rapid decarboxylation of acetyloxy radicals $\mathbf{1 3 1}\left(10^{9} \mathrm{~s}^{-1} \text { at } 80{ }^{\circ} \mathrm{C}\right)^{[179]}$ makes the formation of $\mathrm{CH}_{3} \mathrm{COOH}$ via $\mathrm{H}^{\bullet}$ abstraction from the surrounding $\mathrm{R}-\mathrm{H}$ bonds (e.g. polymer) improbable. Our modified mechanism (path B) explains the formation of $\mathrm{CH}_{3} \mathrm{COOH}$ by molecule induced homolysis in which $\mathrm{R}-\mathrm{H}$ transfers a hydrogen atom to $\mathbf{1 2 9}$ with formation of an intermediate radical $\mathbf{1 3 2}$ which then fragments to $\mathrm{CH}_{3} \mathrm{COOH}$ and 130. In 2008 Tidwell and Henry-Riad proposed[182] the same mechanism to account for products, including $\mathrm{CH}_{3} \mathrm{COOH}$, formed by thermolysis of different $\mathrm{N}$-acyloxytetramethylpiperidines.

Classical radical initiators like peroxides (e.g. dibenzoyl peroxide, BPO) or azo compounds (e.g. AIBN) are highly energetic compounds which must be handled with great care to avoid exothermic runaways or explosions. For instance, heat of decomposition of AIBN ${ }^{[183]}$ and $\mathrm{BPO}^{[184]}$ is about $1.2 \mathrm{~kJ} / \mathrm{g}$ and $1.4 \mathrm{~kJ} / \mathrm{g}$, respectively, and thus about $1 / 3$ of that of the TNT explosive ${ }^{[185]}$ $(4.3 \mathrm{~kJ} / \mathrm{g})$. Between 1964 and 2011, over 80 fatalities and hundreds of injuries occurred due to explosions of organic peroxides. ${ }^{[184]}$ In contrast to this, our $N$-acyloxyamine initiators are inherently safe. They are not oxidizers as the peroxides, their slightly exothermic decomposition in bulk starts only above $150{ }^{\circ} \mathrm{C}$ and generates much less heat (e.g. only about $200 \mathrm{~J} / \mathrm{g}$ with pure 137 , Scheme 29). The $N$-acyloxyamines may be used instead of usual polymerization initiators for initiation at higher temperatures, e.g. for crosslinking of coatings ${ }^{[186]}$ or photoresists in LCD-displays. ${ }^{[187]}$ However, their unique properties are best realized as replacements of peroxides for controlled degradation of polypropylene, also known as controlled rheology of polypropylene (CR-PP). Commercial PP is available in a range of molecular weights (MW). Whereas specific PP grades can be produced by changing process and catalyst system, it is economically much more fa- vorable to modify a standard PP grades in a post reactor process in an extruder (Fig. 1). The principal intent for the CR-PP is an enhancement of physical properties and/or improved processability. Especially for fiber spinning, PP with lower MW and narrower MWD obtained through controlled degradation has processing advantages over conventional reactor made polypropylene. The standard procedure ${ }^{[188]}$ for CR-PP uses organic peroxides, e.g. 134 and $\mathbf{1 3 5}$ which are fed to the compounding extruder together with the PP. Note that the very similar $\mathbf{1 3 6}$ is the infamous triacetone triperoxide (TATP) ${ }^{[189]}$ terrorist explosive. Radicals produced by thermal decomposition of peroxides initiate
Soon after our discovery[176] of $\mathrm{N}$-acyloxyamines as radical initiators in late 1990 s, we started to evaluate them as alternatives to peroxides for CR-PP. Good activity was observed already with $\mathbf{1 2 5}$, however, the more hindered congener $\mathbf{1 2 6}$ was significantly better and active at lower temperature. Finally, after a significant amount of optimization, the liquid compound $\mathbf{1 3 7}$ (Scheme 29) was identified as the optimal candidate for upscaling. Its five-step synthesis $^{[176]}$ starts from the same piperidone $\mathbf{1 0 6}$ as is used for the NMP-alkoxyamine $\mathbf{1 0 8 .}$

The purpose of the $\mathrm{C}_{17}$-chain in $\mathbf{1 3 7}$ is to make the molecule non-volatile, compatible with the apolar PP-matrix and non-migrating. In 2003, 137 was commercialized under the trade name Irgatec ${ }^{\circledR}$ CR 76. As shown in Fig. 6, it is available in easy metering granular form as $c a$. $3.3 \%$ masterbatch in PP granules. It is not classified as dangerous according to EC Directive (1999/45/EC) and requires no special safety and storage requirements. CR-PP with Irgatec ${ }^{\circledR}$ CR 76 is highly efficient in the typical processing temperature range $\left(250-300{ }^{\circ} \mathrm{C}\right)$ and leads to the narrow MWD of the polymer. The resulting melt blown fabrics show tremendous improvements of hydrostatic barrier, air permeability and mechanical properties. ${ }^{[191]}$ Furthermore, the long-term thermal oxidative stability of meltblown fabrics is significantly increased in comparison to fabrics produced with peroxide CR-PP.
Scheme 29. Typical peroxides for CR-PP and active component of $\operatorname{Irgatec}^{\circledR} \mathrm{CR}$ 76.

chain-scission reactions of PP leading to a product with desired molecular and rheological properties. The mechanism of CR-PP with peroxides has been reviewed and re-investigated experimentally and by DFT-calculations by Marque and coworkers ${ }^{[190]}$ in 2010.

Organic peroxides as radical sources for CR-PP suffer from the mentioned safety issues, their decomposition during processing may lead to volatile organic compounds which results in odor formation, and their residues in the end-product may negatively influence its long-term thermal oxidative stability.

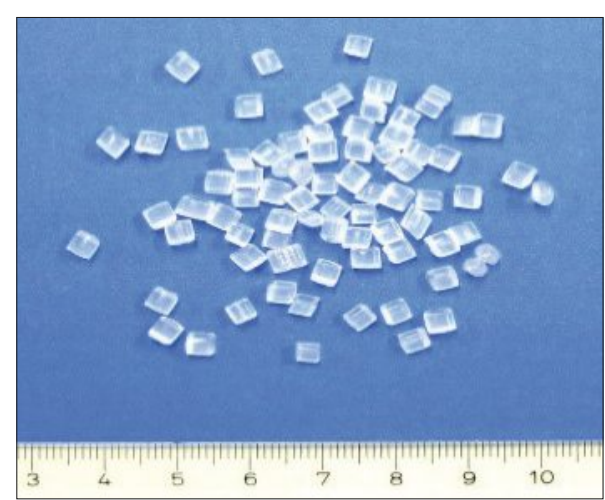

Fig. 6. Irgatec ${ }^{\circledR} \mathrm{CR} 76$ (Masterbatch consisting of ca. $3.3 \%$ of 137 in PP). 
After the development of Irgatec $^{\circledR}$ CR 76, we continued the work on novel thermal radical initiators for some time. Several promising novel approaches were identified, however, for different reasons, no commercialization was realized until now. Only a few representative examples are depicted in Scheme 30. The details on their synthesis and properties are in the indicated patent applications, e.g. 138, ${ }^{[192]}$ 139,[193] 140, 141,[194] 142,[195] 143. ${ }^{[196]}$

\section{Nitroxides for Electrochemical Applications}

The electrochemical redox chemistry of nitroxides offers exciting novel possibilities beyond their use in radical reactions. This chapter briefly summarizes some results we have achieved in 2004-2007. Nitroxides $\mathrm{R}_{1} \mathrm{R}_{2} \mathrm{NO} \mathrm{NO}^{\circ} 14$ undergo 1-electron reduction to hydroxylamine anions 145 or oxidation to oxoammonium cations 146 (Scheme 31). The salts of $\mathbf{1 4 6}$ are well-known reagents ${ }^{[197]}$ for oxidations. The electrochemical oxidation of $\mathbf{1 4 4}$ is often, but not always, reversible. The redox potential of the reversible TEMPO/ $\mathrm{TEMPO}^{+}$couple at $\mathrm{pH}=7$ is about +0.73 $\mathrm{V}$ vs. normal hydrogen electrode (NHE). The reduction TEMPO/TEMPO- ${ }^{-}$occurs irreversibly at $c a$. $-0.38 \mathrm{~V}$. The reason for this irreversibility is the protonation of the anion 145 to give the hydroxylamine $\mathbf{1 4 7}$.

An excellent review ${ }^{[198]}$ of the electrochemical properties of nitroxides as of 2018 is available. The redox potential of nitroxides is easily measured by cyclovoltammetry, and can also be precisely calculated by quantum chemical methods. [199] It can be easily shifted towards more positive values by incorporation of heteroatoms or electron-withdrawing substituents into the nitroxide structure. ${ }^{[199 a, 200]}$ We turned our attention to the electrochemistry of nitroxides after the first report on the organic radical battery (ORB) using redoxactive poly (2,2,6,6-tetramethylpiperidinyloxyl4-yl methacrylate) (PTMA) polymer $\mathbf{1 5 1}$ (Scheme 32) as a cathode material for ORB was published ${ }^{[201]}$ by Nakahara and coworkers in 2002. PTMA provides a cell voltage of $3.58 \mathrm{~V}$ vs. Li, flexibility, lighter weights, decreased environmental impact compared to often used $\mathrm{LiCoO}_{2}$, and inherently fast redox processes leading to higher rate performances. The development of nitroxide-based ORBs was in 2018 quite advanced, and many different nitroxide polymers ${ }^{[202]}$ have been synthesized, recently also for application in redox-flow batteries. ${ }^{203]}$ The known synthesis of PTMA in 2004 used radical polymerization of methacrylate 148 into 149 and subsequent oxidation to afford 151. Unfortunately, in this polymer analogous reaction only $65-81 \%$ of the $\mathrm{NH}$ groups of $\mathbf{1 4 9}$ were oxidized into $\mathrm{NO}^{*}$. Radical polymerization of $\mathbf{1 5 0}$ to $\mathbf{1 5 1}$ is not compatible with its inhibiting NO function, anionic polymerization was reported, but the conditions were far from ideal $\left(-78^{\circ} \mathrm{C}\right.$, diphenylhexyllithium initiator, strongly diluted solution). ${ }^{[204]}$ We were first to apply group transfer polymerization (GTP) to directly polymerize $\mathbf{1 5 0}$ into 151, optionally also in the presence of a bifunctional crosslinker (e.g. ethylene glycol dimethacrylate). The so obtained $\mathbf{1 5 1}$ had $100 \% \mathrm{NO}^{*}$ content. The ORB made with this proprietary[205] (crosslinked) PTMA showed unprecedented charge capacity and high cycling stability. ${ }^{[206]}$

The nitroxide electrode of ORB must be insoluble in the battery electrolyte. We have achieved this by conducting the GTP of $\mathbf{1 5 0}$ in the presence of a small amount of a crosslinker. ${ }^{[206]}$ For other soluble polynitroxides we have developed a proprietary crosslinking method [207] using the principle of the alkoxyamine synthesis through atom transfer radical addition (ATRA). ${ }^{[156]}$ Briefly, a soluble polynitroxide (e.g. linear 151) is reacted with small amount of a polyhalogen derivative (e.g. $\left.\left[\mathrm{CH}_{3} \mathrm{CHBrCOOCH}_{2}-\right]_{4} \mathrm{C}\right]$ ) in the presence of $\mathrm{Cu}^{+}$salts and amine ligand. The result is

an insoluble polynitroxide crosslinked via alkoxyamine bonds.

The amount of energy per weight, i.e. the energy density of ORB should be as high as possible. This value is determined by the amount of charge stored in the battery and its voltage. The charge pure PTMA stores ${ }^{[200]}$ is about $112 \mathrm{mAh} \mathrm{g}^{-1}$, the often used $\mathrm{LiCoO}_{2}$ stores about $140 \mathrm{mAh}$ $\mathrm{g}^{-1}$ when it is cycled between 3 and $4.2 \mathrm{~V}$, corresponding to extracting and inserting about $0.5 \mathrm{Li}$ per $\mathrm{LiCoO}_{2}$. One possibility to increase the energy density is to use nitroxides with higher oxidation potential than that of TEMPO. In 2018 a polymeric indolinone nitroxide with oxidation potential ca. $100 \mathrm{mV}$ higher than PTMA was reported.[202a] We have shown ${ }^{[208]}$ already in 2007 that 3,3,5,5-tetramethylpiperazine-2,6-dione nitroxides, e.g. 152 (Scheme 33) undergo reversible oxidation with potential shifted positively by $c a$. $500 \mathrm{mV}$ as compared to TEMPO. In this case, insoluble polymeric nitroxides were prepared via Rh-catalyzed polymerization of propargyl derivatives, e.g. $\mathbf{1 5 2} \rightarrow \mathbf{1 5 3}$ together with $1-2 \%$ of bifunctional crosslinkers (e.g. $N, N$ '-bis(prop-2-ynyl)oxamide). A battery prototype with $\mathbf{1 5 3}$ indeed displayed ${ }^{208]}$ higher energy density than

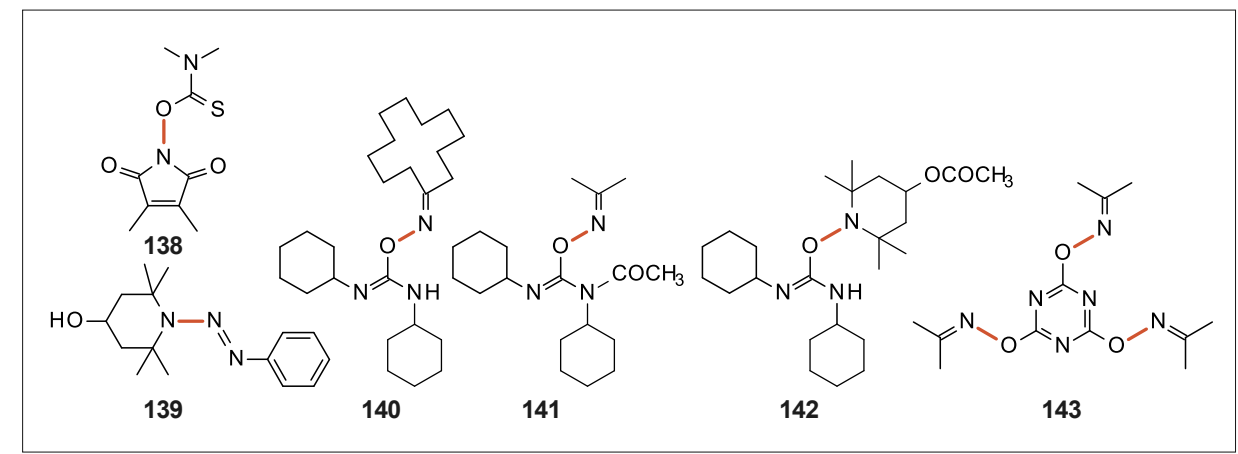

Scheme 30. Novel experimental radical initiators. The bond that undergoes homolysis is marked red.

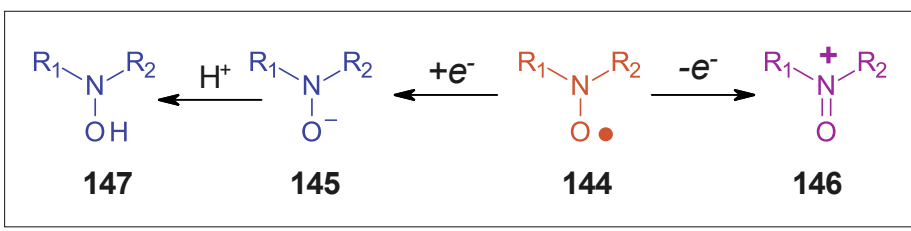

Scheme 31. Redox chemistry of nitroxides.

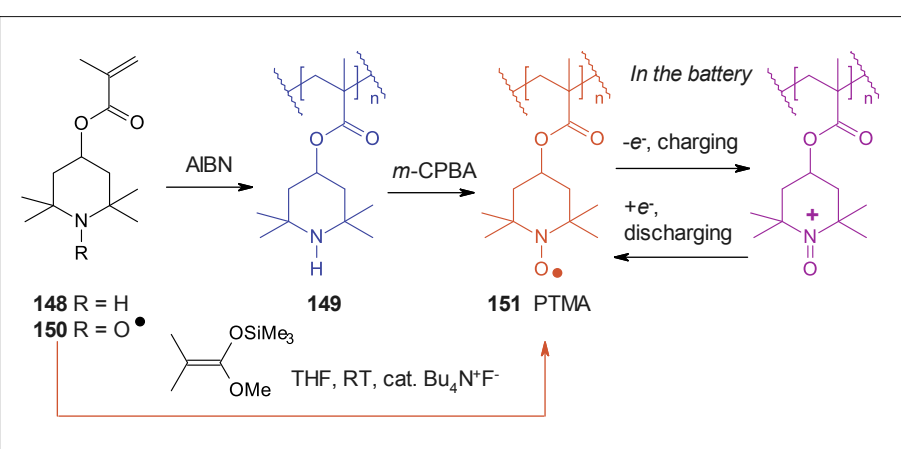

Scheme 32.

Synthesis of PTMA, classical and via GTP (red arrow) and its function in ORB. 
obtained with the best PTMA. Pursuing this direction, we have similarly prepared the spiro-bisnitroxide polymer ${ }^{[200,209]} \mathbf{1 5 4}$ which can store up to $174 \mathrm{mAh} \mathrm{g}^{-1}$ of charge. The two nitroxides of the propargyl monomer for $\mathbf{1 5 4}$ oxidize reversibly in acetonitrile at two different potentials, the 6-membered at $\mathrm{E}_{1 / 2}=0.325 \mathrm{~V}$ vs. $\mathrm{Fc} / \mathrm{Fc}^{+}$ (0.725 V vs. NHE) and the 5-membered at $1.076 \mathrm{~V}$ vs. $\mathrm{Fc} / \mathrm{Fc}^{+}(1.476 \mathrm{~V}$ vs. NHE). Thus, 154 could provide unprecedently high energy density. Unfortunately, in the polymer 154 only the 6-membered nitroxide showed reversible redox behavior. Possibly, the polyacetylene backbone of $\mathbf{1 5 4}$ is not stable at the potential where the 5-membered nitroxide oxidizes. Replacing the polyacetylene in $\mathbf{1 5 4}$ by more oxidatively stable backbone may unveil the very high energy density of such bisnitroxide polymers.

Instead of using crosslinked polymers to provide insoluble polynitroxides for $\mathrm{ORB}$, one can consider monomeric nitroxides which are intrinsically very insoluble. We have prepared a series ${ }^{[210]}$ of 1,3,5-triazine nitroxides and observed that many of them are indeed virtually insoluble in the battery electrolyte (typically ethylene carbonate or dimethyl carbonate). An example of these readily available nitroxides is 155. Noteworthy is also its significantly higher charge capacity (149.4 $\left.\mathrm{mAh} \mathrm{g}^{-1}\right)$ than PTMA (112 $\mathrm{mAh} \mathrm{g}^{-1}$ ).

Safety is a critical issue of lithium-ion batteries (LIB). [211] For example, LIBs do not tolerate charging to potentials above the manufacturer's recommended end of charge potential without degradation in cycle life, the danger of overheating or even fire or explosion. One possibility for protection of LIBs against overcharge is the use of so-called 'redox shuttles'. In the past 20 years, hundreds of compounds ${ }^{[212]}$ were proposed as redox shuttles, amongst them also nitroxides. ${ }^{[213]}$ Importantly, the redox potential of the $\mathrm{NO} / \mathrm{NO}^{+}$couple should be about $300 \mathrm{mV}$ above the maximum operating potential of the positive electrode, to avoid self-discharge of the battery by the shuttle. We have identified 2,2,5,5-tetramethylimidazolidin-4-one nitroxides substituted with electron-withdrawing groups as fulfilling ideally this requirement. [214] For example, the nitroxide $\mathbf{1 5 6}\left(\mathrm{E}_{1 / 2}=1.27\right.$ $\mathrm{V}$ vs. NHE) as electrolyte additive provided efficient overcharge protection of the $\mathrm{Li} / \mathrm{LiFePO}_{4}$ cell. After full charging of $\mathrm{LiFePO}_{4}$ at $3.4 \mathrm{~V}$, the voltage quickly rises above $4 \mathrm{~V}$, where overcharge protection by the redox-shuttle mechanism of $\mathbf{1 5 6}$ sets in, resulting in a stable voltage plateau at 4.1 V. This effect was maintained through many repeated charge-discharge cycles without any deterioration. In 2005, 2,5-di$t$-butyl-1,4-dimethoxybenzene (DBB) ${ }^{[215]}$ was reported as efficient redox shuttle,

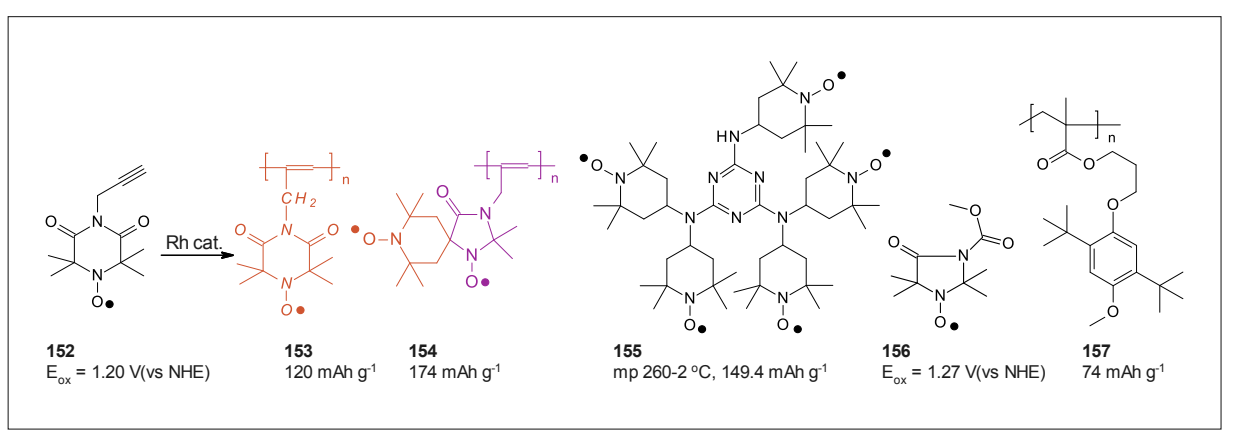

Scheme 33. High voltage and capacity nitroxides 152-155 for ORB. Redox-shuttle nitroxide 156 and redox shuttle inspired polymer 157 for ORB.

based on its ability to form the stable radical cation, $\mathrm{DBB}^{\bullet+}$. We have not tried to develop a better shuttle using this chemistry. Rather, the unique redox behavior of DBB/ $\mathrm{DBB}^{\bullet+}$ couple inspired me to synthesize its polymeric analogue $\mathbf{1 5 7}$ for use as cathode in ORB. This polymer ${ }^{[216]}$ with theoretical charge capacity of $73.9 \mathrm{mAh} \mathrm{g}^{-1}$ performed nicely in a prototype battery, displaying $c a$. $3.8 \mathrm{~V}$ open voltage (vs. Li) and stable cycling behavior. Very similar polymers using the $\mathrm{DBB} / \mathrm{DBB}^{\bullet+}$ redox chemistry were published in the 2017 Evonik-Degussa patent application. ${ }^{217]}$

Unfortunately, the projects on electrochemistry of nitroxides were for various strategic reasons discontinued in 2008, therefore no commercial product resulted from our contributions to this exciting field.

\section{Acknowledgements}

This retrospective summarizes the results of almost 30 years of intensive collaboration with many colleagues and coworkers. Their names are on the cited patents and publications. In particular, I would like to express my sincerest thanks to my technician Lucienne Bugnon-Folger for her tireless effort, extraordinary commitment and highly skilled laboratory work. I further thank the management of Ciba Geigy, Ciba, Ciba SC and BASF for the creative work environment, encouragement and freedom to explore new ideas. I also acknowledge Dr. Rick King for his suggestions and help with the manuscript.

Received: May 30, 2018

[1] G. G. Duthie, Chem. Ind. (London) 1991, 42.

[2] S. Penczek, G. Moad, Pure Appl. Chem. 2008, 80, 2163.

[3] 'Plastics-the Facts 2017', https://www.plasticseurope.org/en/resources/market-data, accessed May 30, 2018

[4] a) J. L. Bolland, G. Gee, Trans. Faraday Soc. 1946, 42, 244; b) J. L. Bolland, G. Gee, Trans. Faraday Soc. 1946, 42, 236; c) J. L. Bolland, Proc. R. Soc. London, Ser. A 1946, 186, 218.

[5] G. Gryn'ova, J. L. Hodgson, M. L. Coote, Org. Biomol. Chem. 2011, 9, 480.

[6] R. Lee, M. L. Coote, Phys. Chem. Chem. Phys. 2016, 18, 24663.

[7] a) K. U. Ingold, D. A. Pratt, Chem. Rev. 2014, 114, 9022; b) S. Al-Malaika, in 'Encycl. Polym.
Sci. Technol. (4th Ed.)', 2014, Vol. 13, p. 1; c) M. Dexter, R. W. Thomas, R. E. King, III, in 'Encycl. Polym. Sci. Technol. (4th Ed.)', 2014, Vol.1, p. 687; d) R. Pfaendner, Polym. Degrad. Stab. 2006, 91, 2249.

[8] a) F. A. Cangelosi, L. H. Davis, R. L. Gray, J. A. Stretanski, D. J. Jakiela, in 'Encycl. Polym. Sci. Technol. (4th Ed.)', 2014, Vol. 14, p. 452; b) G. Gryn'ova, K. U. Ingold, M. L. Coote, J. Am. Chem. Soc. 2012, 134, 12979; c) J. Pospisil, J. Pilar, S. Nespurek, J. Vinyl Addit. Technol. 2007, 13, 119; d) D. Leppard, P. Hayoz, T. Schafer, T. Vogel, F. Wendeborn, Chimia 2002, 56, 216; e) R. V. Todesco, N. Ergenc, Chimia 2002, 56, 225; f) F. Gugumus, Polym. Degrad. Stab. 1993, 39, 117; g) F. Gugumus, Polym. Degrad. Stab. 1993, 40, 167.

[9] K. A. Mesch, in 'Encycl. Polym. Sci. Technol. (4th Ed.)', 2014, Vol. 6, p. 561.

[10] a) 'Plastics Additives Handbook, 5th Ed.', Ed. H. Zweifel, Hanser Munich, 2001; b) H Zweifel, 'Stabilization of Polymeric Materials', Springer-Verlag, Berlin Heidelberg, 1998.

[11] M. Xanthos, D. B. Todd, in 'Encycl. Polym. Sci. Technol. (4th Ed.)' 2014, Vol. 10, p.68.

[12] G. Scott, Chem. Ind. (London) 1987, 841

[13] a) W. O. Drake, J. R. Pauquet, R. V. Todesco, H Zweifel, Angew. Makromol. Chem. 1990, 176-177, 215; b) G. Scott, Polym. Eng. Sci. 1984, 24, 1007.

[14] a) K. Pahnke, J. Brandt, G. Gryn'ova, C. Y. Lin, O. Altintas, F. G. Schmidt, A. Lederer, M. L. Coote, C. Barner-Kowollik, Angew. Chem. Int. Ed. 2016, 55, 1514; b) M. Schaefer, B. Icli, C. Weder, M. Lattuada, A. F. M. Kilbinger, Y. C. Simon, Macromolecules 2016, 49, 1630.

[15] H. Zweifel, Adv. Chem. Ser. 1996, 249, 375.

[16] B. Maillard, K. U. Ingold, J. C. Scaiano, J. Am. Chem. Soc. 1983, 105, 5095

[17] a) M. Dexter, J. D. Spivack, D. H. Steinberg, US 3644482, 1972; b) M. Dexter, J. D. Spivack, D. H. Steinberg, US 3285855, 1966.

[18] H. Zinke, H. J. Lorenz, H. Linhart, DE 2606358 , 1976.

[19] a) J. Pospisil, Polym. Degrad. Stab. 1993, 40, 217; b) J. Pospisil, Polym. Degrad. Stab. 1993, $39,103$.

[20] P. Solera, J. Vinyl Addit. Technol. 1998, 4, 197.

[21] a) Y. M. Sun, J. S. Wu, C. B. Liu, Chin. Sci. Bull. 2007, 52, 1182; b) P. Franchi, M. Lucarini, G. F. Pedulli, L. Valgimigli, B. Lunelli, J. Am. Chem. Soc. 1999, 121, 507.

[22] Y. Ohkatsu, R. Baba, K. Watanabe, J. Jpn. Pet. Inst. 2011, 54, 15.

[23] S. Yachigo, M. Sasaki, Y. Takahashi, F. Kojima, T. Takada, T. Okita, Polym. Degrad. Stab. 1988, 22,63 .

[24] P. Nesvadba, EP 452266, 1991.

[25] P. Nesvadba, EP 466640, 1992.

[26] C. R. H. I. De Jonge, Liebigs Ann. Chem. 1986, 299.

[27] Y.-R. Luo, Editor, 'Comprehensive Handbook of Chemical Bond Energies', CRC Press, 2007, p. 291. 
[28] C. Gyr, Helv. Chim. Acta 1937, 20, 477.

[29] A. Bistrzycki, J. Flatau, Ber. 1895, 28, 989.

[30] P. Karafiloglou, J. P. Catteau, A. LablacheCombier, H. Ofenberg, J. Chem. Soc., Perkin Trans. 2 1977, 1545.

[31] H. Mayerhoefer, H. Schneider, H. Hinsken, W. Mueller, WO 8001566, 1980.

[32] B. B. Dhotare, M. K. Choudhary, S. K. Nayak, Synth. Commun. 2016, 46, 1772.

[33] L. R. Domingo, M. T. Picher, J. Andres, V. S Safont, G. Chuchani, Chem. Phys. Lett. 1997, $274,422$.

[34] D. J. C. Gomes, F. J. Caires, L. S. Lima, A. C. Gigante, M. Ionashiro, Thermochim. Acta $\mathbf{2 0 1 2}$, $533,16$.

[35] P. Nesvadba, DE 4316876, 1993.

[36] P. Nesvadba, DE 4316622, 1993.

[37] P. Nesvadba, DE 4316611, 1993.

[38] P. Nesvadba, EP 589839, 1994.

[39] P. Nesvadba, DE 4220992, 1993.

[40] P. Nesvadba, C. Attinger-Sorato, GB 2257140, 1993.

[41] P. Nesvadba, EP 591102, 1994.

[42] a) P. Nesvadba, L. Bugnon, P. Dubs, S. Evans, Synlett 1999, 863; b) P. Nesvadba, S. Evans, C. Kroehnke, J. Zingg, DE 4432732, 1995; c) P. Nesvadba, S. Evans, R. Schmitt, CA 2132132, 1995.

[43] M. Tinkl, O. Dosenbach, P. Nesvadba, M. Wolff, B. Rotzinger, D. Maeder, WO 2001059000, 2001.

[44] T. Satoh, T. Tsuda, Y. Kushino, M. Miura, M. Nomura, J. Org. Chem. 1996, 61, 6476.

[45] X. Qi, H.-P. Li, X.-F. Wu, Chem.-Asian J. 2016. $11,2453$.

[46] M. Tinkl, S. Evans, P. Nesvadba, WO 9967232 , 1999.

[47] M. Gerster, R. Wicki, Synthesis 2004, 249.

[48] a) J. Rychlý, K. Mosnáčková, L. Rychlá, A. Fiedlerová, G. Kasza, A. Nádor, Z. Osváth, T. Stumphauser, G. Szarka, K. Czaníková, Š. Chmela, B. Iván, J. Mosnáčková, Polym. Degrad. Stab. 2015, 118, 10; b) X. Meng, Z Qiu, Z. Xin, J. Vinyl Addit. Technol. 2013, 19 198; c) Z. Cai, X. Meng, B. Shen, Z. Xin, AsiaPac. J. Chem. Eng. 2012, 7, 111; d) X.-Q. Zhu J. Zhou, C.-H. Wang, X.-T. Li, S. Jing, J. Phys. Chem. B 2011, 115, 3588; e) X. Meng, Z. Xin, Chin. Sci. Bull. 2010, 55, 27; f) V. Filippenko, M. Frenette, J. C. Scaiano, Org. Lett. 2009, 11, 3634; g) K.-S. Focsaneanu, J. C. Scaiano, Helv. Chim. Acta 2006, 89, 2473; h) M. Frenette, P. D. MacLean, L. R. C. Barclay, J. C. Scaiano, J. Am. Chem. Soc. 2006, 128, 16432; i) C. V. Lundgren, A. L. Koner, M. Tinkl, U. Pischel, W. M. Nau, J. Org. Chem. 2006, 71, 1977; j) C. Aliaga, D. R. Stuart, A. Aspee, J. C. Scaiano, Org. Lett. 2005, 7, 3665; k) M. Frenette, C. Aliaga, E. Font-Sanchis, J. C. Scaiano, Org. Lett. 2004, 6, 2579; 1) E. Font-Sanchis, C. Aliaga, E. V. Bejan, R. Cornejo, J. C. Scaiano, J. Org. Chem. 2003, 68, 3199; m) E. FontSanchis, C. Aliaga, R. Cornejo, J. C. Scaiano, Org. Lett. 2003, 5, 1515; n) E. Font-Sanchis, C. Aliaga, K. S. Focsaneanu, J. C. Scaiano, Chem. Commun. 2002, 1576; o) A. Mar'in, L. Greci, P. Dubs, Polym. Degrad. Stab. 2002, 78, 263; p) A. Mar' in, L. Greci, P. Dubs, Polym. Degrad. Stab. 2002, 76, 489; q) E. V. Bejan, E. Font-Sanchis, J. C. Scaiano, Org. Lett. 2001, 3, 4059; r) J. C. Scaiano, A. Martin, G. P. A. Yap, K. U. Ingold, Org. Lett. 2000, 2, 899

[49] H. Lankamp, W. T. Nauta, C. MacLean, Tetrahedron Lett. 1968, 249.

[50] J. P. Catteau, P. Karafiloglou, A. LablacheCombier, J. Chem. Res., Synop. 1980, 305.

[51] a) G. A. DiLabio, K. U. Ingold, S. Lin, G. Litwinienko, O. Mozenson, P. Mulder, T. T. Tidwell, Angew. Chem., Int. Ed. 2010, 49, 5982; b) M. Gomberg, J. Am. Chem. Soc. 1900, 22, 757.

[52] A. Lowenbein, H. Schmidt, Ber. Dtsch. Chem. Ges. B 1927, 60B, 1851.
[53] a) K.-S. Focsaneanu, C. Aliaga, J. C. Scaiano, Org. Lett. 2005, 7, 4979; b) H. Fischer, Chem. Rev. 2001, 101, 3581 .

[54] X. Meng, Z. Xin, Y. Li, Z. Cai, Polym. Degrad. Stab. 2007, 92, 184

[55] P. Nesvadba, L. Bugnon, M. Scheffel, Synth. Commun. 2004, 34, 2797.

56] J. C. Scaiano, WO 2005070913, 2005

[57] H.-G. Korth, Angew. Chem., Int. Ed. 2007, 46, 5274

[58] G. Kruppa, P. Hug, A. Liegard, G. Rist, P. Nesvadba, Helv. Chim. Acta 1993, 76, 1821.

[59] E. Epacher, C. Kroehnke, B. Pukanszky, B Turcsanyi, WO 2001032762, 2001

[60] a) W. Voigt, R. Todesco, Polym. Degrad. Stab. 2002, 77, 397; b) J. R. Pauquet, J. Macromol. Sci., Pure Appl. Chem. 1999, A36, 1717; c) T. Schmutz, R. King, J. R. Pauquet, AddCon Asia '97, Int. Plast. Addit. Modif. Conf., Singapore, Oct. 28-29, 1997.

[61] C.-F. Chiu, C.-Y. Su, E. Lee, EP 2500341, 2012

62] K. Schrinner, P. Xanthopoulos, EP 1291384 , 2003.

[63] K. Imato, M. Nishihara, T. Kanehara, Y Amamoto, A. Takahara, H. Otsuka, Angew. Chem., Int. Ed. 2012, 51, 1138.

[64] K. Imato, T. Ohishi, M. Nishihara, A. Takahara, H. Otsuka, J. Am. Chem. Soc. 2014, 136, 11839

[65] K. Imato, A. Takahara, H. Otsuka, Macromolecules 2015, 48, 5632 .

[66] K. Imato, H. Otsuka, T. Kanehara, S. Nojima, T. Ohishi, Y. Higaki, A. Takahara, Chem. Commun. 2016, 52, 10482.

[67] K. Imato, J. C. Natterodt, J. Sapkota, R. Goseki, C. Weder, A. Takahara, H. Otsuka, Polym Chem. 2017, 8, 2115.

[68] M. Nishihara, K. Imato, A. Irie, T. Kanehara, A Kano, A. Maruyama, A. Takahara, H. Otsuka, Chem. Lett. 2013, 42, 377.

[69] T. Kosuge, K. Imato, R. Goseki, H. Otsuka, Macromolecules 2016, 49, 5903.

[70] a) K. Imato, A. Irie, T. Kosuge, T. Ohishi, M Nishihara, A. Takahara, H. Otsuka, Angew. Chem., Int. Ed. 2015, 54, 6168; b) K. Imato, H. Otsuka, Polymer 2018, 137, 395.

[71] G. R. Schleder, A. Fazzio, J. T. Arantes, J. Comput. Chem. 2017, 38, 2675.

[72] K. Ishizuki, H. Oka, D. Aoki, R. Goseki, H Otsuka, Chem.-Eur. J. 2018, 24, 3170.

[73] T. Sumi, R. Goseki, H. Otsuka, Chem. Commun. 2017, 53, 11885.

[74] H. D. Becker, H. Lingnert, J. Org. Chem. 1982, 47, 1095 .

[75] F. Bigi, G. Casiraghi, G. Sartori, Tetrahedron 1983, 39, 2147.

[76] a) J. N. Chatterjea, N. Prasad, J. Indian Chem. Soc. 1968, 45, 35; b) E. Bernatek, E. Berner, Acta Chem. Scand. 1949, 3, 1117; c) P. Chovin, J. Gunthart, Bull. Soc. Chim. Fr. 1945, 12, 105.

[77] a) P. Nesvadba, Synthesis 2000, 355; b) P. Nesvadba, J. Jandke, WO 9913007, 1999.

[78] R. W. Saalfrank, E. Ackermann, H. Winkler, W. Paul, R. Boehme, Chem. Ber. 1980, 113, 2950.

[79] Y. Chiang, M. Gaplovsky, A. J. Kresge, K. H. Leung, C. Ley, M. Mac, G. Persy, D. L. Phillips, V. V. Popik, C. Roedig, J. Wirz, Y. Zhu, J. Am. Chem. Soc. 2003, 125, 12872.

[80] National Industrial Chemicals Notification and Assessment Scheme (Australia), 'Oracet Orange LGP: Full Public Report', National Occupational Health and Safety Commission, 1999.

[81] a) Y. A. Jackson, K.-S. C. Marriott, Heterocycles 2002, 57, 1897; b) H. D. Becker, C. L. Raston, B. W. Skelton, A. H. White, Aust. J. Chem. 1985, 38, 97.

[82] P. Nesvadba, J. Jandke, WO 9952909, 1999.

[83] H. D. Becker, C. L. Raston, B. W. Skelton, A. H White, Aust. J. Chem. 1985, 38, 85.

84] P. Nesvadba, J. Jandke, WO 2000024736, 2000.

[85] T. Ruch, P. Bugnon, P. Brown, V. Hall-Goulle, WO 2009010521, 2009.
[86] a) T. Deno, M. Takesue, J. Sueltemeyer, US 9217070, 2015; b) T. Deno, M. Takesue, J. Sueltemeyer, WO 2013179237, 2013; c) J. Sueltemeyer, G. De Keyzer, WO 2010081624 , 2010.

[87] Dow Electronic Materials, Evolution of LCDs, Part 1: BCS Technology, http://blog.dowelectronicmaterials.com/en/posts/2016/11/evolution-of-lcds-part1-bcs-technology, accessed May 30. 2018.

[88] Z. Yan, B. Sun, Y. Li, Chem. Commun. 2013, 49, 3790.

[89] a) Y. Liu, F. Wang, J. Chen, X. Wang, H. Lu, L. Qiu, G. Zhang, Macromolecules 2018, 51, 370; b) Y. He, J. T. E. Quinn, D. Hou, J. H. L. Ngai, Y. Li, J. Mater. Chem. C 2017, 5, 12163.

[90] D.-D. Li, J.-X. Wang, Y. Ma, H.-S. Qian, D. Wang, L. Wang, G. Zhang, L. Qiu, Y.-C. Wang, X.-Z. Yang, ACS Appl. Mater. Interfaces 2016, 8, 19312.

[91] a) E. V. Kolyakina, D. F. Grishin, Russ. Chem. Rev. 2011, 80, 683; b) 'Handbook of Radical Polymerization', Eds. K. Matyjaszewski, T. P. Davis, John Wiley \& Sons, Hoboken, 2002; c) F. Tüdos, T. Földes-Berezsnich, Prog. Polym. Sci. 1989, 14, 717; d) F. A. Bovey, I. M. Kolthoff, Chem. Rev. 1948, 42, 491.

[92] a) L. B. Levy, J. Polym. Sci., Polym. Chem. Ed. 1985, 23, 1505; b) J. J. Kurland, J. Polym. Sci., Polym. Chem. Ed. 1980, 18, 1139.

[93] S. C. Ligon, B. Husar, H. Wutzel, R. Holman, R. Liska, Chem. Rev. 2014, 114, 557.

[94] L. B. Levy, J. D. Penrod, Plant/Oper. Prog. 1989, 8, 105.

[95] R. Schwalm, 'UV Coatings: Basics, Recent Developments and New Applications', Elsevier Science \& Technology, 2006.

[96] R. K. Upmacis, W. Bauer, Jr., S. F. Reed, Jr., EP 523965, 1993.

[97] M. E. Gande, P. Nesvadba, R. Pitteloud, EP 672652, 1995

[98] D. Braun, T. Skrzek, S. Steinhauer-Beisser, H. Tretner, H. J. Lindner, Macromol. Chem. Phys. 1995, 196, 573

[99] R. Pitteloud, EP 608198, 1994

[100] H. Meier, H. Kuenzi, H. Fuhrer, G. Rist, Helv. Chim. Acta 1994, 77, 655

[101] J. Pospisil, S. Nespurek, H. Zwiefel, Polym. Degrad. Stab. 1996, 54, 15.

[102] M. V. Motyakin, A. M. Wasserman, P. E. Stott, G. E. Zaikov, J. Appl. Polym. Sci. 2004, 91, 1599.

[103] A. R. Neilson, C. F. Morrison, Org. Process Res. Dev. 2012, 16, 65

[104] Y. Shen, J. Qi, Z. Mao, S. Cui, Org. Lett. 2016, 18, 2722.

[105] R. Pan, L. Hu, C. Han, A. Lin, H. Yao, Org. Lett. 2018, 20, 1974.

[106] a) P. Nesvadba, S. Evans, M. E. Gande, V. H. Von Ahn, R. A. E. Winter, EP 737659, 1996; b) S. Evans, M. E. Gande, P. Nesvadba, V. H. Von Ahn, R. A. E. Winter, EP 737660, 1996.

[107] P. Nesvadba, Synth. Commun. 2000, 30, 2825.

[108] P. Nesvadba, P. Rzadek, G. Rist, Collect. Czech. Chem. Commun. 2001, 66, 1250.

[109] S. Evans, P. Nesvadba, S. Allenbach, EP744392, 1996.

[110] A. Todd, Chemical \& Engineering News 1980 58, 28.

[111] P. Nesvadba, 'Radical Polymerization in Industry', in 'Encycl. Radicals Chem., Biol. Mater'. 2012, Vol. 4, p. 1701.

[112] A. D. Jenkins, R. G. Jones, G. Moad, Pure Appl. Chem. 2010, 82, 483.

[113] a) K. Matyjaszewski, A. H. E. Mueller, Prog. Polym. Sci. 2006, 31, 1039; b) M. Szwarz, Nature 1956, 176, 1168.

[114] 'Controlled and Living Polymerizations', Eds. A. H. E. Müller, K. Matyjaszewski, WileyVCH, Weinheim, 2010.

[115] R. B. Grubbs, R. H. Grubbs, Macromolecules 2017, 50, 6979 . 
[116] K. Matyjaszewski, A. H. E. Mueller, Polym. Prepr. 1997, 38, 6.

[117] a) K. Matyjaszewski, Adv. Mater. 2018, Ahead of Print, DOI: 10.1002/adma.201706441; b) P Krys, K. Matyjaszewski, Eur. Polym. J. 2017, $89,482$.

[118] A. Goto, Y. Tsujii, T. Fukuda, Polymer 2008, 49, 5177.

[119] R. Poli, Chem.-Eur. J. 2015, 21, 6988

[120] a) E. Rizzardo, G. Moad, S. H. Thang, in 'Encycl. Polym. Sci. Technol. (4th Ed.)' 2014, 11, p. 709; b) C. Barner-Kowollik, S. Perrier J. Polym. Sci., Part A Polym. Chem. 2008, 46, 5715.

[121] P. Nesvadba, 'Controlled/living radical polymerization mediated by stable organic radicals', in 'Fundamentals of Controlled/Lining Radical Polymerization', RSC Polym. Chem. Ser. 2013, Vol. 4, p. 112.

[122] a) E. Rizzardo, D. H. Solomon, Aust. J. Chem. 2012, 65, 945; b) D. H. Solomon, J. Polym. Sci., Part A: Polym. Chem. 2005, 43, 5748.

[123] D. H. Solomon, G. Wawerly, E. Rizzardo, W. Hill, P. Cacioli, US 4581429, 1986.

[124] M. K. Georges, R. P. N. Veregin, P. M. Kazmaier, G. K. Hamer, Macromolecules 1993, 26, 2987

[125] J. Nicolas, Y. Guillaneuf, C. Lefay, D. Bertin, D. Gigmes, B. Charleux, Prog. Polym. Sci. 2013, 38, 63 .

[126] 'Nitroxide Mediated Polymerization: From Fundamentals to Applications in Materials Science', Ed. D. Gigmes, RSC Polym. Chem. Ser. 2016, Vol. 19

[127] a) L. Tebben, A. Studer, Angew. Chem., Int. Ed. 2011, 50, 5034; b) H. Karoui, F. Le Moigne, O Ouari, P. Tordo, in 'Stable Radicals', Ed. R. G. Hicks, John Wiley \& Sons Ltd. , Chichester, 2010, p. 173; c) G. I. Likhtenshtein, J Yamauchi, S. Nakatsuji, A. I. Smirnov, R. Tamura, 'Nitroxides. Aplications in Chemistry, Biomedicine, and Materials Science', WileyVCH, Weinheim, 2008; d) L. B. Volodarsky, V. A. Reznikov, V. I. Ovcharenko, 'Synthetic Chemistry of Stable Nitroxides', CRC, Boca Raton, Florida, USA, 1994.

[128] M. V. Ciriano, H.-G. Korth, W. B. van Scheppingen, P. Mulder, J. Am. Chem. Soc. 1999, 121, 6375 .

[129] a) W. Tang, T. Fukuda, K. Matyjaszewski, Macromolecules 2006, 39, 4332; b) T. Kothe, S. Marque, R. Martschke, M. Popov, H Fischer, J. Chem. Soc., Perkin Trans. 2 1998, 1553.

[130] M. Souaille, H. Fischer, Macromolecules 2000, 33, 7378

[131] a) G. Gryn'ova, C. Y. Lin, M. L. Coote, Polym. Chem. 2013, 4, 3744; b) J. L. Hodgson, L. B Roskop, M. S. Gordon, C. Y. Lin, M. L. Coote, J. Phys. Chem. A 2010, 114, 10458.

[132] D. Bertin, D. Gigmes, S. R. A. Marque, P. Tordo, Chem. Soc. Rev. 2011, 40, 2189.

[133] T. Pintauer, K. Matyjaszewski, Chem. Soc. Rev. 2008, 37, 1087.

[134] a) H. Fischer, S. R. A. Marque, P. Nesvadba, Helv. Chim. Acta 2006, 89, 2330; b) H. Fischer, A. Kramer, S. R. A. Marque, P. Nesvadba, Macromolecules 2005, 38, 9974; c) S. Marque, J. Sobek, H. Fischer, A. Kramer, P. Nesvadba, W. Wunderlich, Macromolecules 2003, 36, 3440

[135] a) M.-O. Zink, A. Kramer, P. Nesvadba, Macromolecules 2000, 33, 8106; b) P. Nesvadba, A. Kramer, A. Steinmann, W. Stauffer, WO 9903894, 1999.

[136] Q. Xia, R. B. Grubbs, J. Polym. Sci., Part A: Polym. Chem. 2006, 44, 5128.

[137] V. Sciannamea, R. Jerome, C. Detrembleur, Chem. Rev. 2008, 108, 1104.

[138] S. V. Nikitin, D. A. Parkhomenko, M. V. Edeleva, E. G. Bagryanskaya, J. Polym. Sci. Part A Polym. Chem. 2015, 53, 2546.
[139] T. S. Snowden, ARKIVOC (Gainesville, FL, U. S.) 2012, 24

[140] P. Nesvadba, A. Kramer, M.-O. Zink, DE 19949352, 2000.

[141] a) P. Nkolo, G. Audran, R. Bikanga, P. Bremond, S. R. A. Marque, V. Roubaud, Org. Biomol. Chem. 2017, 15, 6167; b) E. G. Bagryanskaya, S. R. A. Marque, Chem. Rev. 2014, 114, 5011

[142] S. Miele, P. Nesvadba, A. Studer, Macromolecules 2009, 42, 2419.

[143] J. A. M. Hepperle, H. Luftmann, A. Studer, J. Polym. Sci., Part A Polym. Chem. 2012, 50, 2150.

[144] T. Fukuyama, Y. Kajihara, I. Ryu, A. Studer, Synthesis 2012, 44, 2555.

[145] M. Tesch, J. A. M. Hepperle, H. Klaasen, M. Letzel, A. Studer, Angew. Chem., Int. Ed. 2015, 54, 5054 .

[146] M. Buhl, M. Tesch, S. Lamping, J. Moratz, A. Studer, B. J. Ravoo, Chem.-Eur. J. 2017, 23, 6042

[147] Y. Jing, A. Mardyukov, K. Bergander, C. G. Daniliuc, A. Studer, Macromolecules 2014 47, 3595 .

[148] a) X. Wang, M. Emoto, A. Sugimoto, Y Miyake, K. Itto, M. Amasaka, S. Xu, H. Hirata, H. Fujii, H. Arimoto, Tetrahedron Lett. 2014, 55, 2146; b) K. Sakai, K.-i. Yamada, T. Yamasaki, Y. Kinoshita, F. Mito, H. Utsumi, Tetrahedron 2010, 66, 2311; c) Y. Kinoshita, K.-I. Yamada, T. Yamasaki, H. Sadasue, K. Sakai, H. Utsumi, Free Radical Res. 2009, 43, 565 ; d) C. Wetter, J. Gierlich, C. A. Knoop, C. Mueller, T. Schulte, A. Studer, Chem.-Eur. J. 2004, 10, 1156

[149] H. Brunetti, J. Rody, N. Soma, T. Kurumada, DE 2621841, 1976.

[150] A. Kramer, P. Nesvadba, DE 19909767, 1999.

[151] P. Nesvadba, L. Bugnon, R. Sift, J. Polym. Sci., Part A Polym. Chem. 2004, 42, 3332.

[152] P. Nesvadba, L. Bugnon, M. Von Bueren, WO 2004085397, 2004.

[153] D. Bertin, D. Gigmes, S. R. A. Marque, Recent Res. Dev. Org. Chem. 2006, 10, 63

[154] G. Audran, P. Bremond, S. R. A. Marque, Chem. Commun. 2014, 50, 7921 .

[155] P. Nesvadba, Chimia 2006, 60, 832.

[156] K. Matyjaszewski, B. E. Woodworth, X. Zhang, S. G. Gaynor, Z. Metzner, Macromolecules 1998, 31, 5955.

[157] a) H.-J. Kirner, F. Schwarzenbach, P. A. Van Der Schaaf, A. Hafner, V. Rast, M. Frey, P. Nesvadba, G. Rist, Adv. Synth. Catal. 2004, 346, 554; b) A. Hafner, H. J. Kirner, F. Schwarzenbach, P. A. Van Der Schaaf, P. Nesvadba, WO 2001092228, 2001

[158] C.-C. Chang, K. O. Siegenthaler, A. Studer, Helv. Chim. Acta 2006, 89, 2200.

[159] A. Muhlebach, P. Nesvadba, F. Rime, L. Bugnon, Chimia 2008, 62, 799.

[160] S. Grimaldi, J.-P. Finet, F. Le Moigne, A. Zeghdaoui, P. Tordo, D. Benoit, M. Fontanille, Y. Gnanou, Macromolecules 2000, 33, 1141.

[161] a) D. Gigmes, J. Vinas, N. Chagneux, C. Lefay, T. N. T. Phan, T. Trimaille, P.-E. Dufils, Y. Guillaneuf, G. Carrot, F. Boué, D. Bertin, in 'Controlled/Living Radical Polymerization: Progress in RAFT, DT, NMP \& OMRP', Vol. 1024, American Chemical Society, 2009, p. 245; b) F. Chauvin, J.-L. Couturier, P.-E. Dufils, P. Gerard, D. Gigmes, O. Guerret, Y. Guillaneuf, S. R. A. Marque, D. Bertin, P. Tordo, ACS Symp. Ser. 2006, 944, 326.

[162] M. Destarac, Macromol. React. Eng. 2010, 4, 165.

[163] P. Gerard, L. Couvreur, S. Magnet, J. Ness, S. Schmidt, ACS Symp. Ser. 2009, 1024, 361.

[164] C. Auschra, E. Eckstein, R. Knischka, P. Nesvadba, Asia Pacific Coatings J. 2003, 16, 20.
[165] BASF, Formulation Additives by BASF https://www.dispersions-pigments.basf.com portal/load/fid806617/Nafta.pdf, accessed May 30, 2018.

[166] a) A. T. Termaten, M. van der Sluis, F. Pirrung, C. Auschra, Polym. Prepr. 2008, 49, 353; b) F. O. H. Pirrung, C. Auschra, Polym. Prepr. 2005, 46, 316; c) C. Auschra, E. Eckstein, R. Knischka, F. Pirrung, P. Harbers, Eur. Coat. J. 2005, 156; d) C. Auschra, E. Eckstein, R. Knischka, F. Pirrung, P. Harbers, Eur. Coat. J. 2004, 26; e) C. Auschra, E. Eckstein, A. Muehlebach, M.-O. Zink, F. Rime, Prog. Org. Coat. 2002, 45, 83 .

[167] a) F. Pirrung, C. Auschra, in 'Macromolecular Engineering', Vol. 4, Eds. K. Matyjaszewski, Y. Gnanou, L. Leibler, Wiley-VCH, Weinheim, 2007, p. 2135; b) F. O. H. Pirrung, P. H. Quednau, C. Auschra, Chimia 2002, 56 , 170.

[168] a) N. R. Cameron, O. Lagrille, P. A. Lovell, B. Thongnuanchan, Polymer 2014, 55, 772; b) N. R. Cameron, O. Lagrille, P. A. Lovell, B. Thongnuanchan, ACS Macro Lett. 2012, 1 , 1262 ; c) A. Debuigne, D. Chan-Seng, L. Li, G. K. Hamer, M. K. Georges, Macromolecules 2007, 40, 6224; d) E. Drockenmuller, J. P. Lamps, J.-M. Catala, Macromolecules 2004, 37, 2076; e) J. Ruehl, L. Hill Nicole, D. Walter Eric, G. Millhauser, R. Braslau, Macromolecules 2008, 41, 1972.

[169] a) T. Hintermann, P. Nesvadba, A. Kramer, J. Fink, WO 03074572, 2003; b) T. Hintermann, A. Kramer, P. Nesvadba, J. Fink, Polym. Prepr. 2002, 43, 86

[170] E. G. Bagryanskaya, S. R. A. Marque, 'Kinetic aspects of nitroxide mediated polymerization', in 'Nitroxide Mediated Polymerization: From Fundamentals to Applications in Materials Science', Ed. D. Gigmes, RSC Polym. Chem. Ser. 2016, 19, 45.

[171] A. Nilsen, R. Braslau, J. Polym. Sci., Part A: Polym. Chem. 2006, 44, 697.

[172] K. A. Payne, P. Nesvadba, J. Debling, M. F. Cunningham, R. A. Hutchinson, ACS Macro Lett. 2015, 4, 280.

[173] J. Debling, P. Nesvadba, K.-D. Hungenberg, WO 2015134591, 2015

[174] K. A. Payne, J. Debling, P. Nesvadba, M. F. Cunningham, R. A. Hutchinson, Eur. Polym. J. 2016, 80, 186.

[175] R. F. Malherbe, R. A. E. Winter, J. P. Galbo, R. A. Behrens, A. Mar, P. J. Schirmann, R. Seltzer, EP 309400, 1989

[176] M. Roth, R. Pfaendner, P. Nesvadba, M.-O Zink, WO 2001090113, 2001.

[177] A. Gaudel-Siri, D. Siri, P. Tordo, Chem.Phys Chem. 2006, 7, 430.

[178] a) D.-L. Versace, Y. Guillaneuf, D. Bertin, J. P. Fouassier, J. Lalevee, D. Gigmes, Org. Biomol. Chem. 2011, 9, 2892; b) D. Gigmes, A. Gaudel-Siri, S. R. A. Marque, D. Bertin, P. Tordo, P. Astolfi, L. Greci, C. Rizzoli, Helv. Chim. Acta 2006, 89, 2312.

[179] A. Fraind, R. Turncliff, T. Fox, J. Sodano, L. R. Ryzhkov, J. Phys. Org. Chem. 2011, 24 809.

[180] D. Belekian, P. Cassagnau, J.-J. Flat, S Quinebeche, L. Autissier, D. Bertin, D. Siri, D. Gigmes, Y. Guillaneuf, P. Chaumont, E Beyou, Polym. Chem. 2013, 4, 2676.

[181] D. L. Marshall, G. Gryn'ova, M. L. Coote, P. J Barker, S. J. Blanksby, Int. J. Mass Spectrom. 2015, 378, 38.

[182] H. Henry-Riyad, T. T. Tidwell, ARKIVOC (Gainesville, FL, U. S.) 2008, 113.

[183] E. Moukhina, Thermochim. Acta 2015, 621, 25

[184] S. H. Liu, H. Y. Hou, J. W. Chen, S. Y. Weng, Y. C. Lin, C. M. Shu, Thermochim. Acta 2013 , 566, 226.

[185] V. I. Pepekin, S. A. Gubin, Combustion, Explosion, and Shock Waves 2007, 43, 212. 
[186] K. Studer, P. Nesvadba, T. Jung, J. Benkhoff, K. Powell, C. Lordelot, Prog. Org. Coat. 2008, $61,119$.

[187] H. Kura, K. Sameshima, K. Kunimoto, P. Nesvadba, M. Ohwa, WO 2010108835, 2010.

[188] a) H. Azizi, I. Ghasemi, Polym. Test. 2004, 23, 137; b) C. Tzoganakis, J. Vlachopoulos, A. E. Hamielec, Polym. Eng. Sci. 1988, 28, 170.

[189] F. Dubnikova, R. Kosloff, J. Almog, Y. Zeiri, R. Boese, H. Itzhaky, A. Alt, E. Keinan, J. Am Chem. Soc. 2005, 127, 1146.

[190] D. Bertin, M. Leblanc, S. R. A. Marque, D. Siri, Polym. Degrad. Stab. 2010, 95, 782.

[191] a) A. Psarreas, C. Tzoganakis, N. McManus, A. Penlidis, Polym. Eng. Sci. 2007, 47, 2118; b) A. Schneider, M. Roth, Chem. Fibers Int. 2006, 56, 177.

[192] P. Nesvadba, J. Benkhoff, L. Bugnon, K. Powell, T. Jung, WO 2006051047, 2006.

[193] P. Nesvadba, L. Bugnon Folger, J.-L. Birbaum, M. Faller, A. Carroy, WO 2010112410, 2010.

[194] P. Nesvadba, L. Bugnon Folger, A. Carroy, M. Faller, B. Spony, WO 2010128062, 2010.

[195] P. Nesvadba, L. Bugnon Folger, A. C. Carroy, M. Faller, WO 2010079102, 2010.

[196] P. Nesvadba, L. Bugnon Folger, A. Carroy, M. Faller, WO 2014064064, 2014.

[197] a) J. M. Bobbitt, C. Bruckner, N. Merbouh, Org. React. 2009, 74, 103; b) N. Merbouh, J. M. Bobbitt, C. Brueckner, Org. Prep. Proced. Int. 2004, 36, 3.
[198] J. E. Nutting, M. Rafiee, S. S. Stahl, Chem. Rev. 2018, 118, 4834.

[199] a) K. Zhang, B. B. Noble, A. C. Mater, M. J. Monteiro, M. L. Coote, Z. Jia, Phys. Chem. Chem. Phys. 2018, 20, 2606; b) G. Gryn'ova, J. M. Barakat, J. P. Blinco, S. E. Bottle, M. L. Coote, Chem.-Eur. J. 2012, 18, 7582; c) J. P. Blinco, J. L. Hodgson, B. J. Morrow, J. R. Walker, G. D. Will, M. L. Coote, S. E. Bottle, J. Org. Chem. 2008, 73, 6763.

[200] P. Nesvadba, L. Bugnon, P. Maire, P. Novak, Chem. Mater. 2010, 22, 783.

[201] K. Nakahara, S. Iwasa, M. Sato, Y. Morioka, J. Iriyama, M. Suguro, E. Hasegawa, Chem. Phys. Lett. 2002, 351.

[202] a) K.-A. Hansen, J. Nerkar, K. Thomas, S. E. Bottle, A. P. O'Mullane, P. C. Talbot, J. P. Blinco, ACS Appl. Mater. Interfaces 2018, 10, 7982; b) K.-A. Hansen, J. P. Blinco, Polym. Chem. 2018, 9, 1479; c) T. Janoschka, M. D. Hager, U. S. Schubert, Adv. Mater. 2012, 24, 6397.

[203] T. Hagemann, J. Winsberg, M. Grube, I. Nischang, T. Janoschka, N. Martin, M. D. Hager, U. S. Schubert, J. Power Sources 2018, $378,546$.

[204] J. Allgaier, H. Finkelmann, Macromol. Rapid Commun. 1993, 14, 267.

[205] P. Nesvadba, L. Bugnon, WO2006131451, 2006

[206] L. Bugnon, C. J. H. Morton, P. Novak, J. Vetter, P. Nesvadba, Chem. Mater. 2007, 19, 2910.
[207] P. Nesvadba, L. Bugnon, WO2007115939, 2007.

[208] P. Nesvadba, L. Bugnon Folger, T. Hintermann, WO2008155247, 2008.

[209] P. Nesvadba, L. Bugnon, M. Frey, WO2008031733, 2008.

[210] P. Nesvadba, L. Bugnon, WO2007107468, 2007.

[211] P. G. Balakrishnan, R. Ramesh, T. Prem Kumar, J. Power Sources 2006, 155, 401.

[212] Z. Chen, Y. Qin, K. Amine, Electrochim. Acta 2009, 54, 5605 .

[213] M. Taggougui, B. Carre, P. Willmann, D Lemordant, J. Power Sources 2007, 174, 643.

[214] T. Hintermann, P. Nesvadba, M. Frey, WO2008110466, 2008.

[215] a) Z. Zhang, L. Zhang, J. A. Schlueter, P. C. Redfern, L. Curtiss, K. Amine, J. Power Sources 2010, 195, 4957; b) J. R. Dahn, J. Jiang, L. M. Moshurchak, M. D. Fleischauer, C. Buhrmester, L. J. Krause, J. Electrochem. Soc. 2005, 152, A1283.

[216] P. Nesvadba, L. B. Folger, P. Maire, P. Novak, Synth. Met. 2011, 161, 259.

[217] U. Schubert, A. Wild, B. Haeupler, WO2017032583, 2017. 